\title{
Transcryptomic Analysis of Human Brain-Microvascular Endothelial Response to -Pericytes: Cell Orientation Defines Barrier Function
}

\author{
Lisa Kurmann ${ }^{1}$, Michal Okoniewski ${ }^{2} \oplus$, Omolara O. Ogunshola ${ }^{3}$, Brigitte Leeners ${ }^{1}$, Bruno Imthurn ${ }^{1}$ \\ and Raghvendra K. Dubey ${ }^{1,4, *}$
}

check for updates

Citation: Kurmann, L.; Okoniewski, M.; Ogunshola, O.O.; Leeners, B.;

Imthurn, B.; Dubey, R.K.

Transcryptomic Analysis of Human Brain-Microvascular Endothelial Response to -Pericytes: Cell Orientation Defines Barrier Function. Cells 2021, 10, 963. https://doi.org/ 10.3390/cells10040963

Academic Editors: Alexander E. Kalyuzhny and Georg Breier

Received: 30 March 2021

Accepted: 16 April 2021

Published: 20 April 2021

Publisher's Note: MDPI stays neutral with regard to jurisdictional claims in published maps and institutional affiliations.

Copyright: (C) 2021 by the authors Licensee MDPI, Basel, Switzerland. This article is an open access article distributed under the terms and conditions of the Creative Commons Attribution (CC BY) license (https:/ / creativecommons.org/licenses/by/ $4.0 /)$.
1 Department of Reproductive Endocrinology, University Hospital Zurich, 8952 Schlieren, Switzerland; lisa.kurmann@usz.ch (L.K.); brigitte.leeners@usz.ch (B.L.); bruno.imthurn@uzh.ch (B.I.)

2 ID Scientific IT Services, ETH Zurich, 8092 Zurich, Switzerland; michal.okoniewski@id.ethz.ch

3 Zurich Center Integrative Physiology (ZIHP), Vetsuisse Faculty, Institute of Veterinary Physiology, University of Zurich, 8057 Zurich, Switzerland; larao@access.uzh.ch

4 Department of Pharmacology \& Chemical Biology, University of Pittsburgh, Pittsburgh, PA 15219, USA

* Correspondence: Raghvendra.dubey@usz.ch

\begin{abstract}
Pericytes facilitate blood-brain barrier (BBB) integrity; however, the mechanisms involved remain unclear. Hence, using co-cultures of human cerebral microvascular endothelial cells (ECs) and vascular pericytes (PCs) in different spatial arrangements, as well as PC conditioned media, we investigated the impact of PC-EC orientation and PC-derived soluble factors on EC barrier function. We provide the first evidence that barrier-inducing properties of PCs require basolateral contact with ECs. Gene expression analysis (GEA) in ECs co-cultured with PCs versus ECs alone showed significant upregulation of 38 genes and downregulation of 122 genes. Pathway enrichment analysis of modulated genes showed significant regulation of several pathways, including transforming growth factor- $\beta$ and interleukin-1 regulated extracellular matrix, interferon and interleukin signaling, immune system signaling, receptor of advanced glycation end products (RAGE), and cytokine-cytokine receptor interaction. Transcriptomic analysis showed a reduction in molecules such as pro-inflammatory cytokines and chemokines, which are known to be induced during BBB disruption. Moreover, cytokine proteome array confirmed the downregulation of key pro-inflammatory cytokines and chemokines on the protein level. Other molecules which influence BBB and were favorably modulated upon EC-PC co-culture include IL-18 binding protein, kallikrein-3, CSF2 CSF3, CXCL10, CXCL11 (downregulated) and IL-1-R4; HGF, PDGF-AB/BB, PECAM, SERPIN E1 (upregulated). In conclusion, we provide the first evidence that (1) basolateral contact between ECs and PCs is essential for EC barrier function and integrity; (2) in ECs co-cultured with PCs, the profile of BBB disrupting pro-inflammatory molecules and cytokines/chemokines is downregulated; (3) PCs significantly modulate EC mechanisms known to improve barrier function, including TGF- $\beta$ regulated ECM pathway, anti-inflammatory cytokines, growth factors and matrix proteins. This human PC-EC co-culture may serve as a viable in vitro model for investigating BBB function and drug transport.
\end{abstract}

Keywords: pericyte; hCMEC/D3; co-culture; blood-brain barrier; orientation; transcriptome; conditioned media; micro array

\section{Introduction}

The neurovascular unit (NVU) constitutes a highly evolved network of many different cell types that together form a selectively permeable boundary between the systemic circulation and the interstitial fluid of the brain, the so-called blood-brain barrier (BBB). In addition to a single layer of endothelial cells (ECs), also astrocytes, pericytes (PCs), microglia and neurons hold critical functions in maintaining the integrity of the vessel wall [1,2]. PCs have long been an overlooked player in the field of BBB research. More 
recently, however, these mural cells have gained increasing attention as several studies have revealed the importance of PCs with regard to a properly functioning endothelial barrier. In vivo studies using viable pericyte-deficient mouse models provide evidence that PCs are critical for BBB formation and PC loss results in severe vessel leakage [1,2]. Additionally, PC degeneration is associated with several central nervous system (CNS) disorders such as Alzheimer's disease, stroke or amyotrophic lateral sclerosis (ALS) [3]. Apart from PC depletion, disturbed signaling between ECs and PCs contributes to barrier leakage and disease states. Communication between the two cell types is known to occur via paracrine signaling involving a plethora of soluble factors, but also direct cell-to-cell contacts in form of so-called peg-socket interactions, gap junctions and adhesion plaques play a significant role [4].

Transport across the endothelial barrier can be partitioned into two major pathways: paracellular and transcellular [5]. The paracellular permeability is restricted to small, water-soluble molecules with a Stoke's radius of less than 3 to $6 \mathrm{~nm}$ and is regulated by a complex interplay between different junctional proteins and the actin cytoskeleton of cells $[5,6]$. Transcellular routes, which include the steps of endocytosis, transport across the cell lumen and exocytosis, are mainly responsible for macromolecular transport. The uptake of molecules can be carrier- or receptor-mediated or non-specific via adsorptionmediated endocytosis or pinocytosis [5,7]. Understanding the regulatory mechanisms of transport pathways across the endothelial barrier is of great importance, particularly in the field of drug delivery into the central CNS. Several promising therapeutics developed for CNS diseases have failed in clinical trials due to the lack of an appropriate delivery system across the BBB $[7,8]$.

Due to the high complexity of in vivo data analysis, researchers make use of different in vitro models for the BBB that include a combination of two or more cell types of the NVU [9]. Although these models represent a vastly simplified picture of the in vivo situation, they are of great importance when it comes to understand the contribution of a single cell type to the function of the BBB [9]. Using such simplified 2D models, many studies have improved our basic understanding of how PCs affect the function of the endothelial barrier and, importantly, the mechanisms behind it [10-12]. Observed variations in published data may in part be explained by the various possibilities of assembling EC-PC co-culture models in different constellations.

To test our hypothesis that PCs interact with ECs to improve barrier function, we first investigated the impact of different spatial arrangements of ECs and PCs on the function of the endothelial barrier. Specifically, we seeded the PCs on the opposite side of the endothelial cell layer on the basolateral side of the transwell insert (indirect) or together with the ECs on the apical side in direct contact. Moreover, a non-contact model with PCs plated on the well surface was also included. Additionally, we added pericyte-conditioned media (PCM) to inserts culturing endothelial monolayers in order to evaluate the effect of soluble factors secreted by PCs. Using different approaches for measuring barrier function, we assessed whether PCs modulate para- and/or transcellular transport pathways in ECs. Furthermore, using transcriptomic gene expression analysis and proteome arrays, we explored potential signaling pathways and modulatory molecules by which PCs improve EC barrier function.

\section{Materials and Methods}

\subsection{Cell Culture}

hBVPs: Human Brain Vascular Pericytes (HBVPs, ScienCell, CA, USA) between 4-10th passage were cultured in Poly-L-Lysine- (PLL-) coated flasks $\left(2 \mu \mathrm{g} / \mathrm{cm}^{2}\right)$ under standard tissue culture conditions $\left(37^{\circ} \mathrm{C}, 5 \% \mathrm{CO}_{2}\right)$ in growing media consisting of DMEM/F12 supplemented with antibiotic-antimycotic (AA; $100 \mu \mathrm{g} / \mathrm{mL}$ streptomycin, $100 \mu \mathrm{g} / \mathrm{mL}$ penicillin and $0.025 \mu \mathrm{g} / \mathrm{mL}$ amphotericin B), Glutamax $(1 \times)$ and $10 \%$ FBS. Media was changed every two or three days until sub-confluency. 
hCMEC/D3: The human Cerebral Microvascular Endothelial Cell line (hCMEC/D3) [13] was kindly provided by Dr. Pierre-Olivier Couraud (Institute COCHIN, Paris, France). Cells between 34th and 39th passage were cultured on rat-tail-collagen-coated $(250 \mu \mathrm{g} / \mathrm{mL}$ in $80 \% \mathrm{EtOH})$ flasks under standard tissue culture conditions $\left(37^{\circ} \mathrm{C}, 5 \% \mathrm{CO}_{2}\right)$ in complete growing media (EC basal media (EndoGRO Basal Medium supplemented with $0.2 \%$ EndoGRO-LS Supplement, $5 \mathrm{ng} / \mathrm{mL}$ rh EGF, $4 \mathrm{mM}$ L-Glutamine, $0.75 \mathrm{U} / \mathrm{mL}$ Heparin Sulfate, $50 \mu \mathrm{g} / \mathrm{mL}$ Ascorbic Acid, $1 \mathrm{ng} / \mathrm{mL}$ bFGF, antibiotic-antimycotic $(100 \mu \mathrm{g} / \mathrm{mL}$ streptomycin, $100 \mu \mathrm{g} / \mathrm{mL}$ penicillin and $0.025 \mu \mathrm{g} / \mathrm{mL}$ amphotericin B))) supplemented with $5 \%$ FBS. Media was changed every two or three days, and cells were passaged after confluency was reached.

hASMC: Human Coronary Artery Smooth Muscle Cells (LONZA, Walkersville, MD, USA) between 6-9th passage were cultured in non-coated flasks under standard tissue culture conditions $\left(37^{\circ} \mathrm{C}, 5 \% \mathrm{CO}_{2}\right)$ in growing media consisting of M231 culture medium supplemented with antibiotic-antimycotic (AA; $100 \mu \mathrm{g} / \mathrm{mL}$ streptomycin, $100 \mu \mathrm{g} / \mathrm{mL}$ penicillin and $0.025 \mu \mathrm{g} / \mathrm{mL}$ amphotericin B) and SMGS (5\% v/v FCS, $2 \mathrm{ng} / \mathrm{mL}$ human basic Fibroblast Growth Factor, $0.5 \mathrm{ng} / \mathrm{mL}$ human Epidermal Growth Factor, $5 \mathrm{ng} / \mathrm{mL}$ Heparin, $5 \mu \mathrm{g} / \mathrm{mL}$ insulin and $0.2 \mu \mathrm{g} / \mathrm{mL}$ BSA). Media was changed every two or three days until sub-confluency.

\subsection{Barrier Function Studies}

Determination of endothelial cell barrier function was achieved by three different methods: Trans-endothelial electric resistance measurements (TEER), macromolecular tracer assays and electric cell substrate impedance measurements.

\subsection{Transendothelial Electric Resistance (TEER)}

For TEER measurements in real-time, a cellZcope instrument (nanoAnalytics GmbH, Münster, DE) was used. Permeable transparent PET membrane inserts of $0.4 \mu \mathrm{m}$ pore size and 24-well format (Corning Incorporated, NY, USA, Falcon 353095) were coated with poly-L-Lysine on the basolateral side and with rat tail collagen $(250 \mu \mathrm{g} / \mathrm{mL}$ in $80 \% \mathrm{EtOH})$ on the apical side for $1 \mathrm{~h}$ at $37{ }^{\circ} \mathrm{C}$ and washed twice with sterile $\mathrm{H}_{2} \mathrm{O}$, before they were incubated for another hour in PC growing media (5\% FBS). For the co-culture models, hBVPs were seeded either on the basolateral or on the apical side of the insert at a density of 25,000 cells $/ \mathrm{cm}^{2}$. After adherence of the PCs was achieved (3 h), hCMEC/D3 were seeded in the apical chamber at a cell density of 100,000 cells $/ \mathrm{cm}^{2}$ in $150 \mu \mathrm{L}$ EndoGro growing media. This set-up allows the two cell types to form direct contacts through the pores of the membrane [14]. Media in the basolateral chamber consisted of PC growing media (5\% FBS). After 3 days, media was changed to $2 \%$ FBS and hydrocortisone $(1 \mu \mathrm{g} / \mathrm{mL})$ was added. For measurements, inserts were added to the cellZcope instrument (lower chamber: $1 \mathrm{~mL}$ media, upper chamber: $0.5 \mathrm{~mL}$ media). Establishment of a proper barrier function was monitored by recording resistance values of the inserts every hour, and treatments, when necessary, were only applied once the cells reached a stable baseline. All measurements were normalized to the values of a coated insert without any cells and results are depicted in $\%$ of control or in absolute TEER values in $\mathrm{ohm}^{*} \mathrm{~cm}^{2}$.

\subsection{Macromolecular Tracer Assay}

For the macromolecular tracer assay, cells were seeded into the inserts as described above. Treatments, when necessary, were only applied after cells reached stable TEER baseline as was determined by measurements with the cellZcope instrument. FITC-labeled dextran molecules ( $1 \mathrm{mg} / \mathrm{mL}$ in media) of two different sizes ( 4 and $40 \mathrm{kDa}$ ) were added to the upper chamber of the inserts in $100 \mu \mathrm{L} /$ insert, with $500 \mu \mathrm{L}$ of media in the basolateral chamber. Samples $(100 \mu \mathrm{L})$ were collected from the basolateral chamber after $40 \mathrm{~min}$ and added to a fluoro-block 96-wellplate. Fluorescent intensity was determined by using a Tecan Spectrofluorometer reader (Tecan, Salzburg, AU) (excitation at $490 \mathrm{~nm}$ and 
emission at $520 \mathrm{~nm}$ ). Relative fluorescent intensity was determined by normalizing to the control sample.

\subsection{Electric Cell Substrate Impedance Sensing (ECIS)}

Impedance measurements were performed with the xCELLigence RTCA system (Omni Life Sciences, Basel, $\mathrm{CH}$ ). Wells of 16-well E-plates were coated with $40 \mu \mathrm{L}$ rattail-collagen $(250 \mu \mathrm{g} / \mathrm{mL}$ in $80 \% \mathrm{EtOH})$ and/or PLL $\left(2 \mu \mathrm{g} / \mathrm{cm}^{2}\right)$ for $1 \mathrm{~h}$ at $37{ }^{\circ} \mathrm{C}$, washed $2 \times$ with sterile $\mathrm{ddH}_{2} \mathrm{O}$ and subsequently incubated with $50 \mu \mathrm{L}$ of EC growing media for at least $1 \mathrm{~h}$ in the tissue culture incubator. The baseline was measured in each well according to manufacturer's protocol, before hCMEC/D3 cells were seeded at a density of 100,000 cells $/ \mathrm{cm}^{2}$ in $100 \mu \mathrm{L}$ growing media. Impedance was recorded in real time every hour or as specified and was converted to the dimensionless parameter cell index (arbitrary unit) by the xCELLigence RTCA software. Noted values on the $y$-axis were labeled as cell index (or normalized cell index, if normalized to the timepoint before treatment).

\subsection{Conditioned Media (CM)}

Pericyte (PC-) and smooth muscle cell (SMC-) CM.

HBVPs and hASMCs were cultured in $75 \mathrm{~cm}^{2}$ - (or $25 \mathrm{~cm}^{2}-$ ) culturing flasks in growing media until confluency was reached. After 2 washing steps with $\mathrm{HBSS}\left(+\mathrm{Mg}^{2+}+\mathrm{Ca}^{2+}\right)$, $10 \mathrm{~mL}$ (or $3.3 \mathrm{~mL}$ ) serum-free DMEM/F12 supplemented with Glutamax $(1 \times)$ was added for $24 \mathrm{~h}$. CM was collected and centrifuged at $1000 \times g$ for $10 \mathrm{~min}$ at $4{ }^{\circ} \mathrm{C}$. The supernatant was carefully collected, aliquoted and frozen immediately at $\times 80^{\circ} \mathrm{C}$ until further use. Control consisted of non-conditioned media, which was not added to cells, but prepared at the same time as the CM and otherwise treated identically. For CM-treatments, the collected CM was supplemented with Glutamax $(1 \times)$, antibiotic-antimycotic (AA; $100 \mu \mathrm{g} / \mathrm{mL}$ streptomycin, $100 \mu \mathrm{g} / \mathrm{mL}$ penicillin and $0.025 \mu \mathrm{g} / \mathrm{mL}$ amphotericin B) and $5 \%$ or $2 \%$ FBS, depending on the experiment.

\section{Co-Culture-Conditioned Media (Co-CM)}

HBVPs were cultured on the basolateral side of transwell inserts with or without endothelial cells on the apical side for 5 days, before inserts were removed (same media conditions as used in normal co-culture experiments on inserts). New inserts containing established endothelial monolayers were then added to the wells containing conditioned media.

\subsection{Cell Count}

hCMEC/D3 cells were plated in 48-wellplates and allowed to grow to confluence before treatment was added for the specified period of time. Thereafter, cells were washed $2 \times$ with HBSS $\left(-\mathrm{Mg}^{2+}-\mathrm{Ca}^{2+}\right)$, trypsinized with $0.5 \%$ trypsin and counted with a Coulter Counter (Coulter Electronics, Luton, UK). Relative cell number was assessed by normalizing to the control treated samples.

\subsection{Crystal Violet Staining (CVS)}

hCMEC/D3 cells were plated in 48-wellplates and allowed to grow to confluence. After treatment, paraformaldehyde (PFA, 4\%) was added to the media (1:1) for 2 min, before media was removed and fresh PFA (4\%) was added for $15 \mathrm{~min}$ at RT without shaking. Subsequently, cells were washed once with $\mathrm{HBSS}\left(+\mathrm{Mg}^{2+}+\mathrm{Ca}^{2+}\right)$, and twice with $\mathrm{ddH}_{2} \mathrm{O}$ for 3 min each wash. Crystal violet staining (CVS) solution $(0.5 \%$ aqueous solution in $25 \%$ Methanol) was added for $10 \mathrm{~min}$ at RT while shaking slightly. Cells were washed extensively with $\mathrm{ddH}_{2} \mathrm{O}$ until no coloring of the water was visible anymore. Solubilization of the cells was achieved by adding 1\% SDS aqueous solution while shaking at RT for about 5 to $10 \mathrm{~min}$. The solution was transferred to a 96-wellplate for reading the absorbance at $595 \mathrm{~nm}$ using a Tecan Spectrofluorometer reader (Tecan, Salzburg, AU). 


\subsection{Microarray Analysis}

For the microarray samples, ECs were seeded alone or with PCs on the opposite side of permeable PET membrane inserts of $0.4 \mu \mathrm{m}$ pore size and 6-well format (Corning Incorporated, NY, USA, Costar 3450). After 7 days in culture ( $2 \%$ steroid-free FCS (charcoalstripped) in presence of hydrocortisone), cells were trypsinized, centrifuged and lysed in $300 \mu \mathrm{L}$ RNA lysis buffer (Zymo Research, CA, USA). Samples were frozen at $-80^{\circ} \mathrm{C}$ until further processing. Total RNA was then extracted by using the Quick-RNA MiniPrep Kit (ZymoResearch, CA, USA, R1055) according to the manufacture's protocol. RNA integrity was checked by calculating the ratio of absorbance at $260 \mathrm{~nm}$ and $280 \mathrm{~nm} / 230 \mathrm{~nm}$, respectively. The samples were frozen at $-80^{\circ} \mathrm{C}$ for microarray analysis using Affymetrix Clariom S Assay, human (Applied Biosystems by Thermo Fisher Scientific Inc, OK, USA, 902927) as previously described [15]. For transcriptome analysis, fragmented biotin-labeled ds cDNA was hybridized to Clariom ${ }^{\mathrm{TM}} \mathrm{S}$ arrays (Clariom ${ }^{\mathrm{TM}} \mathrm{S}$ arrays, human). After staining, arrays were scanned with Affymetrix Gene-Chip Scanner-3000-7G while quality control analysis was performed using GeneChip Command Console Software (GCC) v5.0. Transcriptome analysis was done at the transcriptomics core facility at the Center for Molecular Medicine Cologne (CMMC). Differentially regulated genes were determined with the Transcriptome Analysis Console (TAC, Applied Biosystems by Thermo Fisher Scientific Inc, OK, USA) after uploading the CEL files, based on a foldchange cut-off of \pm 1.5 (Log2 FC \pm 0.59 ) and FDR P-value of 0.05. Pathway analysis was performed using NCATS BioPlanet on the Enrichr website, which includes more than 1600 human pathways from publicly available sources [16]. The microarray data are deposited in the public Gene Expression Omnibus (GEO) database under the accession no. GSE168514 (access date 19th April 2021).

\subsection{Cytokine Proteome Array}

For analysis of cytokine expression in co- and mono-cultured ECs, the Proteome Profiler Human XL Cytokine Array Kit (R\&D Systems, MN, USA, ARY022B) was used. Cells were grown exactly as described in the microarray section above. After trypsinization and centrifugation, the pellet was lysed in lysis buffer 17 (R\&D Systems, MN, USA) supplemented with aprotinin, leupeptin and pepstatin $(10 \mu \mathrm{g} / \mathrm{mL}$ each), and after processing according to the user's manual, they were frozen at $-80^{\circ} \mathrm{C}$ until further use. Incubation of the ready-to-use membranes was done $\mathrm{o} / \mathrm{n}$ with equal amounts of samples (175 $\mu \mathrm{g}$ in $1.5 \mathrm{~mL}$ ), as was determined by BCA analysis. The following detection of the proteins was performed exactly as described in the user's manual and for the exposure of the membranes Hyperfilm ECL (Amersham, $\mathrm{CH}$ ) were used in a CAWOMAT 2000 IR film developer (Wiroma AG, Niederscherli, $\mathrm{CH}$ ). Experiment was performed two times with independently prepared samples. Signal density of each spot was determined with the imageJ software after background subtraction and values represented in the graphs denote mean values of each protein from the two experiments.

\subsection{Western Blot Analysis}

For Western blot analysis, cells were grown exactly as described in the microarray section above. After trypsinization and centrifugation, the pellet was lysed in lysis buffer (containing $20 \mathrm{mM}$ Tris pH 7.5, 1\% Triton X- 100, $150 \mathrm{mM} \mathrm{NaCl}, 1 \mathrm{mM}$ EGTA, 1 mM EDTA, $2.5 \mathrm{mM}$ sodium phosphate, $1 \mathrm{mM} \beta$-glycerophosphate, $1 \mathrm{mM}$ sodium vanadate, 0.5 PMSF and $0.2 \%$ SDS). Concentration of each sample was determined with the Pierce bicinchoninic acid (BCA) Assay Kit according to the manufacturer's protocol. Equivalent amounts $(10 \mu \mathrm{g})$ of protein from whole-cell lysates were separated on 10\% SDS-polyacrylamide gels. After transfer to a nitrocellulose membrane by the method of wet electroblotting, the membrane was blocked with $5 \%$ milk at RT for $1 \mathrm{~h}$. Incubation with the primary antibody was performed $\mathrm{o} / \mathrm{n}$ at $4{ }^{\circ} \mathrm{C}$. After washing, the membrane was incubated with the secondary antibody for $1 \mathrm{~h}$ at RT and washed again. For detection of proteins with IR Dyes, the Odyssey LI-COR system (LI-COR, Nebraska, USA) was used. For peroxidase-conjugated 
secondary antibodies, chemiluminescent substrates (Pierce, Rockford, USA) were added according to manufacturer's instruction. Peroxidase activity was detected by exposing the membranes to XOMAT LS films, which were developed with the CAWOMAT 2000 IR film developer (WIROMA AG, Niederscherli, $\mathrm{CH}$ ).

\subsection{Statistical Analysis}

Experiments were performed at least 3 times, and data are represented as mean $\pm \mathrm{SD}$ unless stated otherwise. Statistical evaluation was performed by using R. If ANOVA assumptions were met parametric testing was performed with one-way ANOVA and subsequent Tukey's HSD multiple pairwise comparisons. If either one of the ANOVA assumptions were not met, non-parametric testing was performed with Kruskal-Wallis rank sum test and subsequent pairwise Wilcoxon-test with Benjamini-Hochberg corrections for multiple comparisons. Microarray data analysis was performed with the Transcriptome Analysis Console (TAC, Applied Biosystems), which uses generalized linear models (Limma-based, eBayes). The generation of probe set intensity values was performed by 'Signal Space Transformation' (SST)-RMA normalization method and background correction.

\section{Results}

\subsection{Preliminary Experiments}

In the following, the barrier function of endothelial cells (ECs) is measured by three different methods: trans-endothelial electric resistance measurements (TEER), macromolecular tracer assays and electric cell substrate impedance sensing (ECIS) with the xCELLigence system. While the first two systems are well established and most-commonly used for in vitro barrier function measurements, the used ECIS system (xCELLigence RTCA) is usually used for monitoring cell growth, adherence or motility. However, several studies have also applied the same system for measuring barrier function [17-20]. In the Supplementary Materials, we provide measurements that demonstrate the usability of the system and show that for example hydrocortisone, a well-known barrier-inducer [21], increases barrier function as measured with this system. To demonstrate barrier disruption, we used hypoxic conditions as well as the inflammatory mediator thrombin to show a decrease in the measured barrier function (Supplementary Figure S1).

\subsection{Effect of Different Co-Culture Arrangements on Barrier Function}

In a first step, we examined the effect of different spatial pericyte-endothelial cell (PC-EC) arrangements on barrier function. ECs were always plated on the apical side of the transwell inserts, while PCs were plated either on the basolateral side ("indirect") or on the apical side in direct contact with ECs (direct). For the direct model, cells were plated in two different constellations: PCs plated first (PC_EC direct) or ECs plated first (EC_PC direct) (Figure 1).

In order to assess the impact of the different models on the barrier function, TEER was measured by means of a cellZcope instrument. In addition, the permeability of the barrier towards FITC-labelled dextran molecules in different sizes (4 kDa and $40 \mathrm{kDa}$ ) was assessed.

As the ratio of PCs to ECs can vary greatly according to different locations and sources even within the brain [3,4,22], barrier function was assessed using different ratios of PCs to ECs (1:1, 1:2 and 1:4), all of which increased the barrier function to a similar extent (Supplementary Figure S2). In subsequent experiments, a ratio of 1:4 (PCs:ECs) was used.

Growing the cells in the indirect co-culture model resulted in a significant upregulation of resistance measurements and a simultaneous decrease in permeability towards FITCdextran, if compared to an endothelial monolayer (Figure $2 b, c$ ). This clearly indicates that the barrier function is enhanced in presence of PCs. In order to assess whether the observed improvement is not only due to the additional cell layer, co-culture experiments with smooth muscle cells (SMCs) instead of PCs were also performed. SMCs had no effect 
on barrier function as can be derived from Figure 2d. Additionally, the measured TEER value of co-cultured cells was higher than cumulative values for EC and PC monocultures (Supplementary Figure S3).

\section{EC and PC orientation in co-cultures}

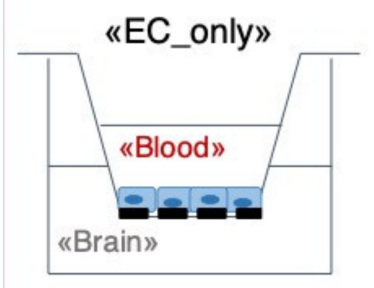

- Membrane

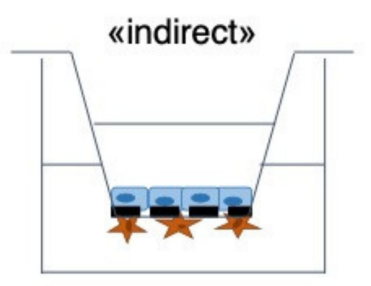

Endothelial cells
«PC_EC direct»
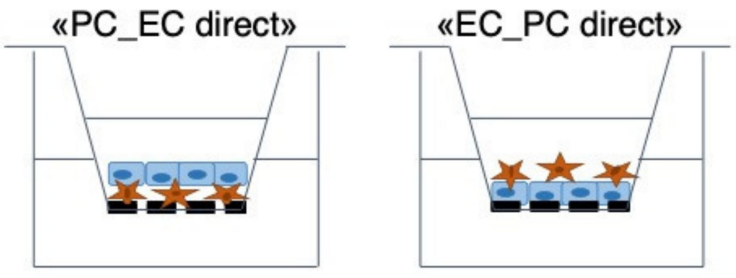

Figure 1. Schematic illustration of the experimental design of BBB models that were used in this study. "EC_only": endothelial cells (ECs) are plated on the apical side of a 24-well-plate insert with a pore-size of $0.4 \mu \mathrm{m}$. "indirect": Pericytes (PCs) are plated on the basolateral side of the insert, and in a second step (after $3 \mathrm{~h}$ ), ECs are plated on the apical side, allowing contact of the two cell types through the membrane. "PC_EC direct": PCs are plated on the apical side of inserts first, and after 3 h, ECs are plated on top of PCs. "EC_PC direct": ECs are plated first, and after 3 h, PCs are seeded on top of them.

a)

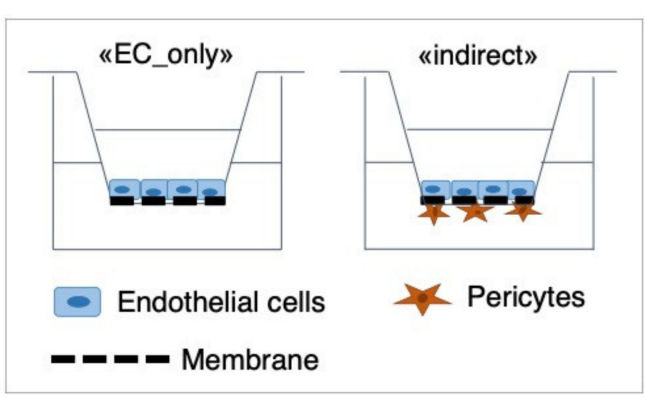

c)

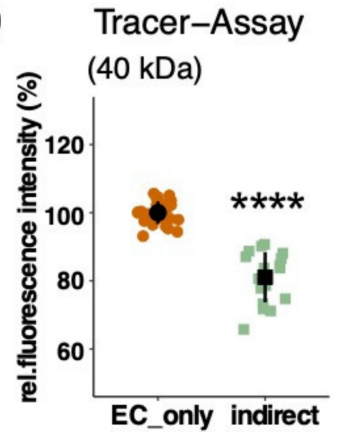

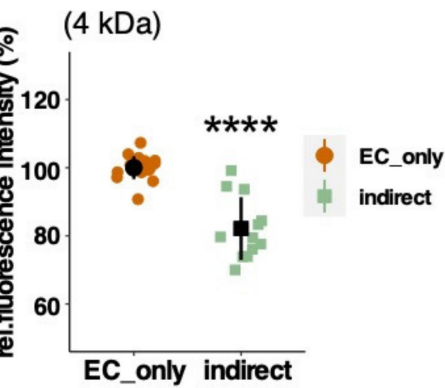

b)

TEER

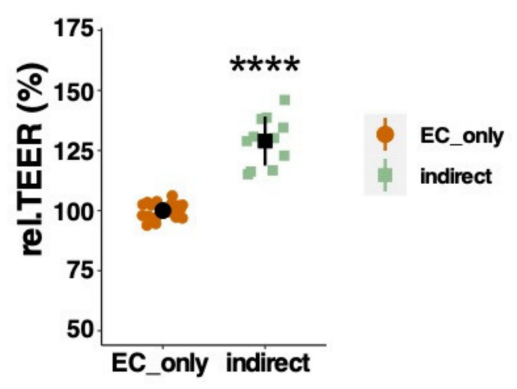

d)

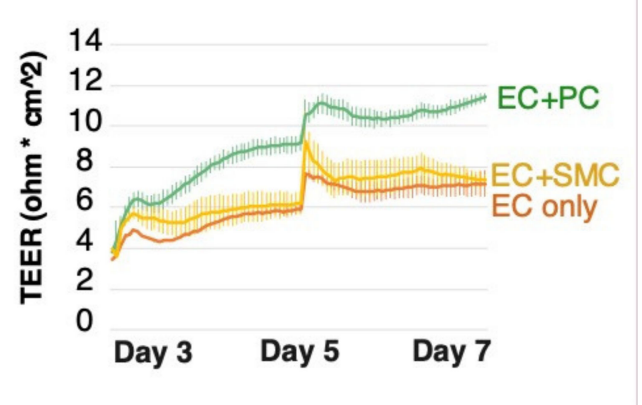

Figure 2. Pericytes (PCs) increase barrier function of endothelial cells (ECs). Schematic representation of the indirect co-culture model (a) ECs were cultured on transwell inserts alone (EC_only) or with PCs (indirect) (b,c) and SMCs (d) on the basolateral side of the insert (indirect). Cells were cultured for 7 days before barrier function was assessed. Relative trans-endothelial electric resistance (TEER) measurements were performed with a CellZcope instrument (b). Relative fluorescence intensity measured by macromolecular tracer assay with FITC-labeled dextran molecules of 40 and $4 \mathrm{kDa}$ (c). Representative real-time TEER measurement of ECs alone and in co-culture with PCs or SMCs (d). Experiments were performed at least three times in triplicates and data represent mean $\pm \mathrm{sd}$. ${ }^{* * *} p<0.0001$, compared to "EC_only". 
If PCs were cultured on the same side of the insert together with ECs, TEER measurements were lower than in EC monolayers, which was accompanied by a higher permeability towards tracer molecules. This observation was irrespective of seeding order (Figure $3 \mathrm{a}, \mathrm{b}$ ) and also applied when PCs were seeded on top of an established EC monolayer (Supplementary Figure S4a). The results of the direct co-cultures were further verified by means of ECIS measurements with the xCELLigence system in real-time. Impedance measurements were significantly lower if PCs were co-cultured together with ECs in any seeding order with direct contact (Figure 2c, Supplementary Figure S4b).

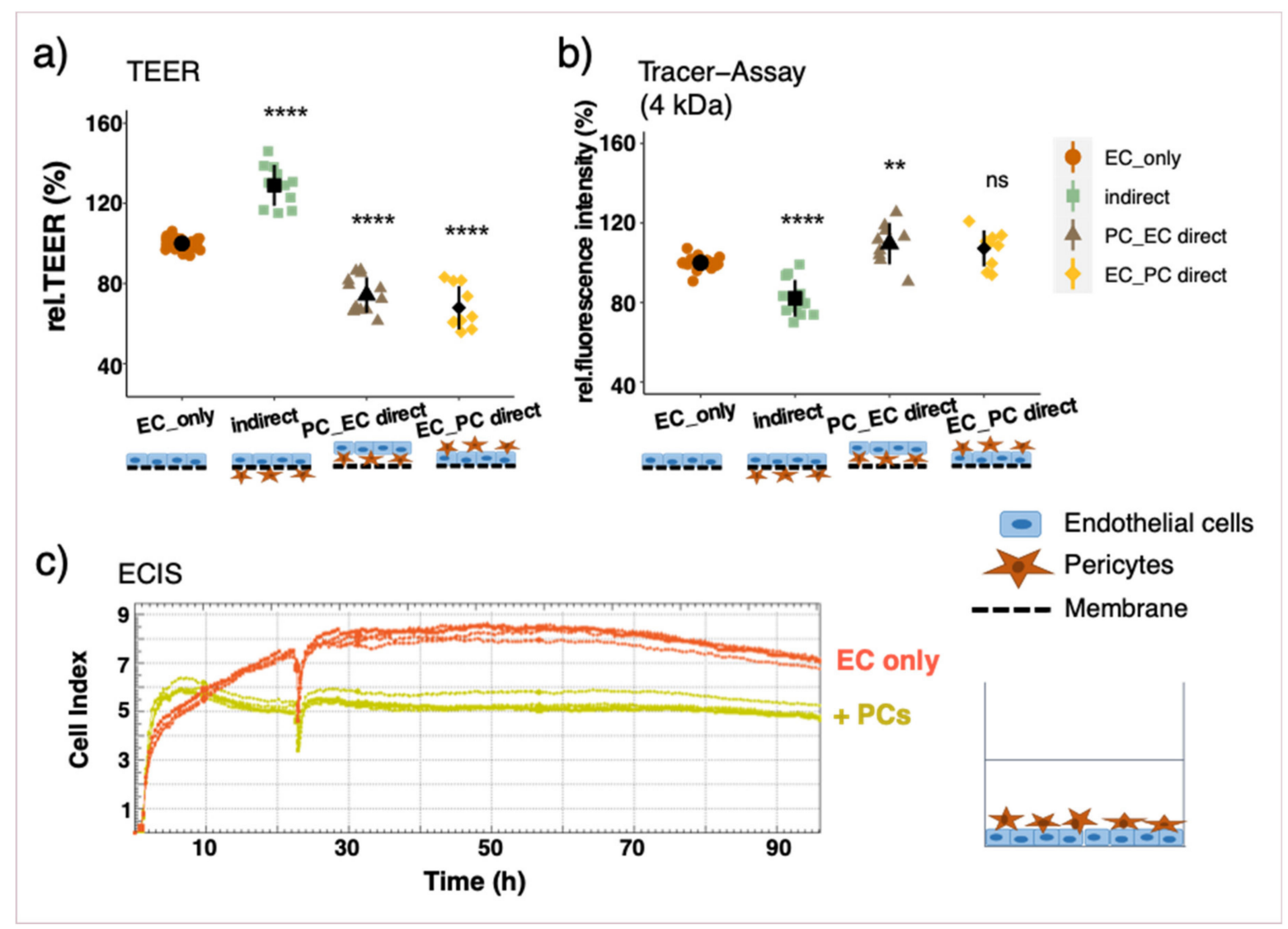

Figure 3. Measurements of endothelial barrier function with and without pericytes (PCs) in different constellations. Endothelial cells (ECs) were cultured on transwell inserts alone (EC_only), with PCs on the opposite side of the insert (indirect) or on the same side (PC_EC direct: PCs seeded first; and EC_PC direct: ECs seeded first). Cells were cultured for 7 days before barrier function was assessed. Relative trans-endothelial electric resistance (TEER) measurements with a CellZcope instrument (a). Relative fluorescence intensity measured by macromolecular tracer assay with FITC-dextran $4 \mathrm{kDa}$ (b); results for $40 \mathrm{kDa}$ FITC-dextran are comparable (data not shown). Representative ECIS measurements in real-time with the xCELLigence System: ECs were seeded into eplates $3 \mathrm{~h}$ before PCs were added on top (c). Experiments have been performed at least three times in triplicates and data represent mean $\pm \mathrm{sd}$. ${ }^{* *} p<0.01,{ }^{* * * *} p<0.0001$, compared to "EC_only".

\subsection{Effect of Pericyte-Conditioned Media on Barrier Function}

To assess a possible involvement of soluble factors secreted by PCs, the barrier function of EC monolayers was measured after treatment with PC-conditioned media (PCM) in different set-ups. Treating an established endothelial monolayer with PCM in the basolateral chamber for three days did not have a significant impact on barrier function (Supplementary Figure S5) as measured by TEER and tracer assays. To test whether a prolonged treatment with PCM is necessary for barrier improvement, ECs were treated with PCM as soon as seeded into the inserts. Contrary to our expectations, the barrier function was significantly compromised as shown by a reduction in TEER and by an 
increased permeability to $4 \mathrm{kDa}$ FITC-dextran (Figure $4 \mathrm{~b}, \mathrm{c}$ ). The permeability to bigger FITC-dextran molecules, however, was not affected (40 kDa) (Figure $4 \mathrm{~d})$ ). A similar effect was observed when PCs were plated on the bottom of the well-plate with no direct contact to ECs (non-contact model) as is shown by a decrease in TEER (Supplementary Figure S6). This non-contact model reflects a similar condition as the prolonged PCM treatment. Furthermore, the effect of conditioned media from co-cultured and mono-cultured PCs was compared with respect to barrier function. By treating EC monolayers with PCM from co-cultured and mono-cultured PCs on the basolateral side for 3 days, no differential effect on barrier function was observed (Supplementary Figure S7).

a)

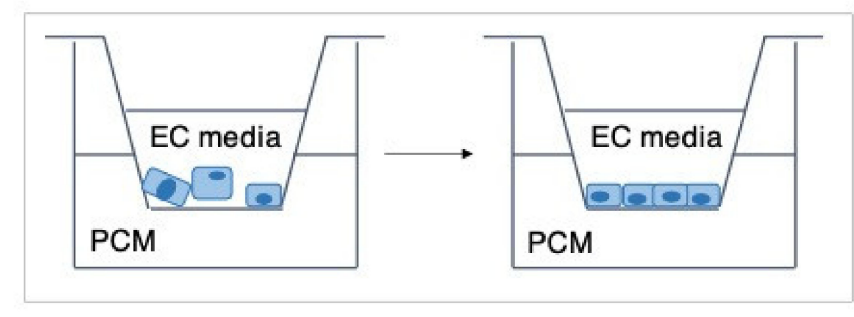

b)

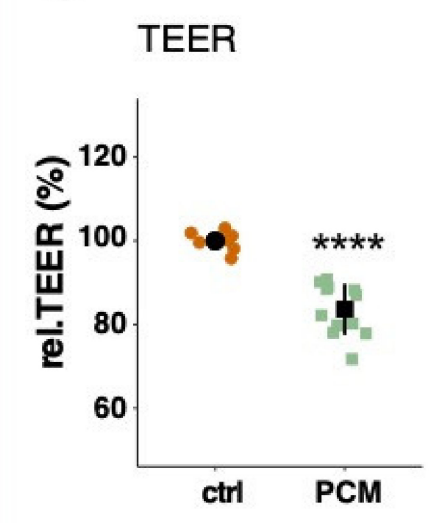

c)

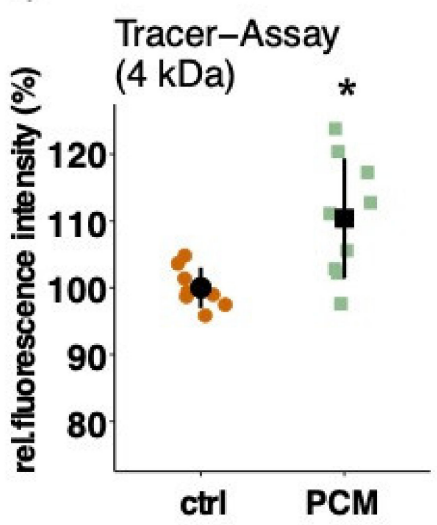

d)

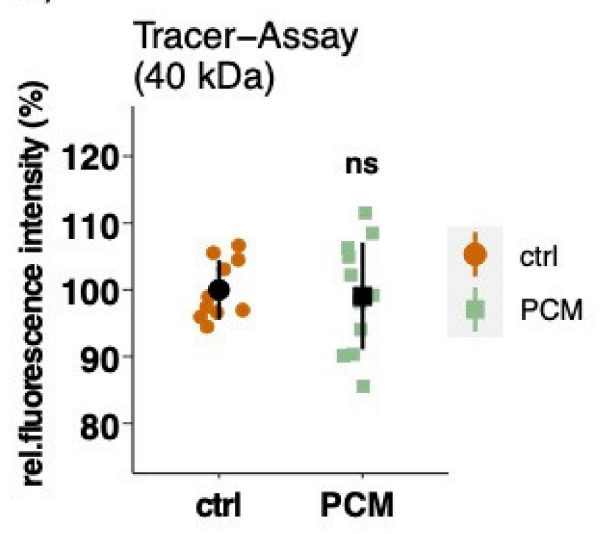

Figure 4. Measurements of endothelial barrier function after prolonged basolateral PCM treatment. Endothelial cells (ECs) were plated on transwell inserts with EC growing media in the apical chamber and PCM in the basolateral chamber (a). Relative TEER measurements (b) and macromolecular tracer assays with FITC-labeled dextran of 4 and $40 \mathrm{kDa}$ (c,d) were performed after 7 days in culture. Measurements were performed at least three times in triplicates and data represent mean \pm sd. ns $p>0.05,{ }^{*} p<0.05,{ }^{* * * *} p<0.0001$.

PCM treatment on the apical side of an established EC monolayer led to a significant decrease after only $6 \mathrm{~h}$ of treatment as shown by real-time impedance measurement as well as TEER measurements (Figure $5 a, b)$. These findings are further supported by an increase in permeability towards FITC-dextran molecules of 4 and $40 \mathrm{kDa}$ (Figure 5c, $40 \mathrm{kDa}$ as representative for both FITC-dextran sizes). When ECs were apically treated with conditioned media from SMCs, the same effect was observed (Supplementary Figure S8). This suggests a general rather than a pericyte-specific influence, which is more likely related to EC's apico-basal polarity. 


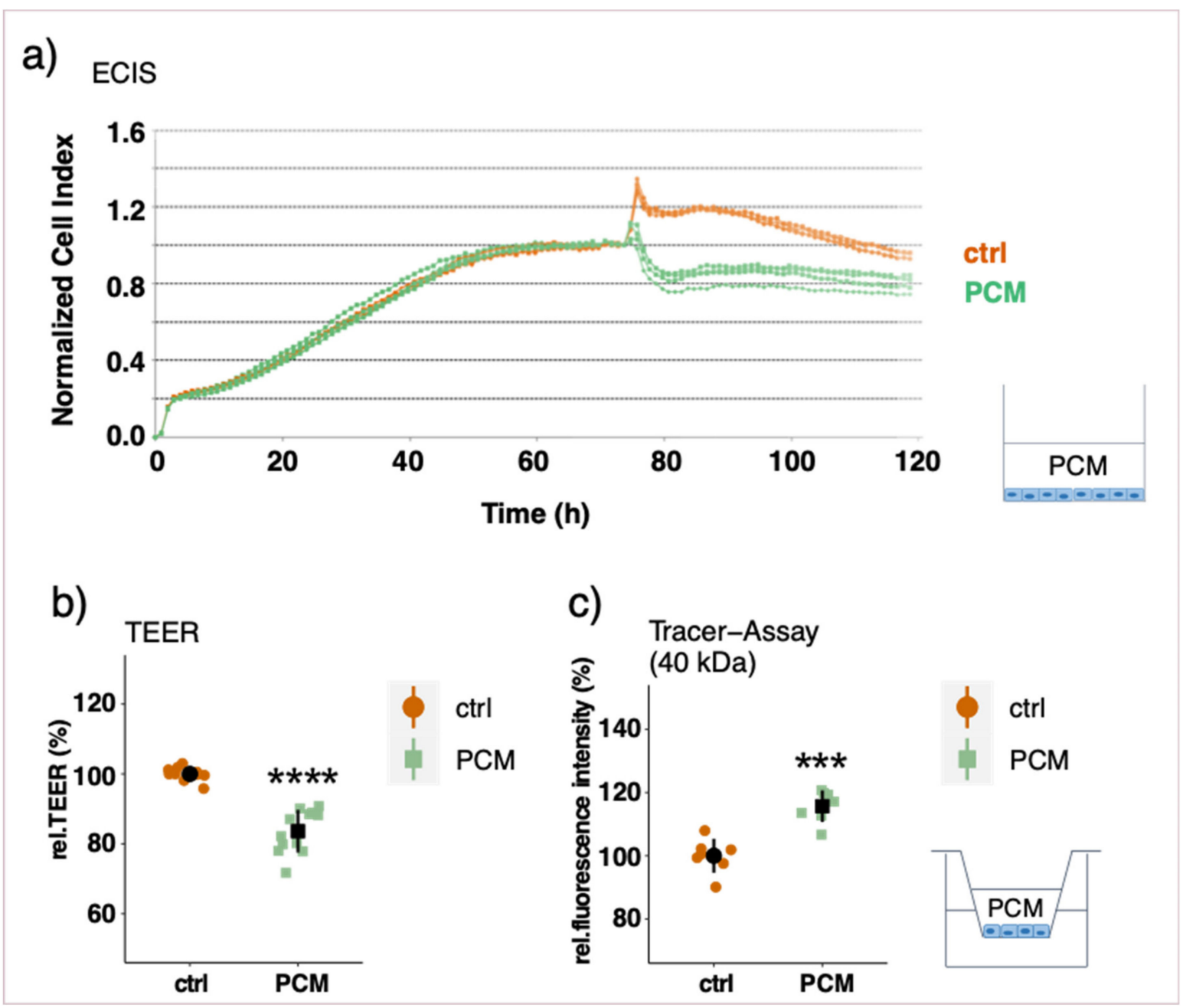

Figure 5. Measurements of endothelial barrier function after apical PCM treatment of an EC monolayer. ECs were cultured in eplates $(\mathbf{a})$ or on transwell inserts $(\mathbf{b}, \mathbf{c})$. After a stable barrier function was established (6-7 days), PCM was added to the apical side for $24 \mathrm{~h}$. Representative real-time ECIS measurements with the xCELLigence system (a), relative transendothelial electric resistance (TEER) measurements with a CellZcope instrument (b) and macromolecular tracer assays with FITC-labeled dextran of $40 \mathrm{kDa}$ (representative also for $4 \mathrm{kDa}$ ) (c). Experiments were performed at least three times in triplicates and data represent mean $\pm \mathrm{sd}$. ${ }^{* * *} p<0.001,{ }^{* * * *} p<0.0001$.

For the purpose of investigating whether the effect of apical PCM treatment is a result of reduced cell viability, crystal violet staining (CVS) as well as cell counting experiments were performed. The results of both assays clearly showed that PCM treatment did not decrease cell viability after 6 or 48 h of treatment (Supplementary Figure S9).

\subsection{Gene Expression Array}

In order to deepen our knowledge about genes which play a role in improving barrier function in co-cultured cells, transcriptomic analysis of ECs cultured alone and in the indirect co-culture model with PCs was performed by means of a microarray. Differentially regulated genes (DRGs) were determined by comparison of gene expression in co- vs. mono-cultured cells (Supplementary Figure S10). Quality control by means of principle component analysis (PCA) of the different samples shows a clear-cut difference between samples from EC mono- and co-cultures (Supplementary Figure S11). A total of 160 DRGs were detected, with 122 genes down- and 38 genes upregulated (Figure $6 a, b)$. A list of the top ten genes up- and downregulated in co-cultured ECs is provided in the Supplementary Materials (Supplementary Tables S1 and S2). 


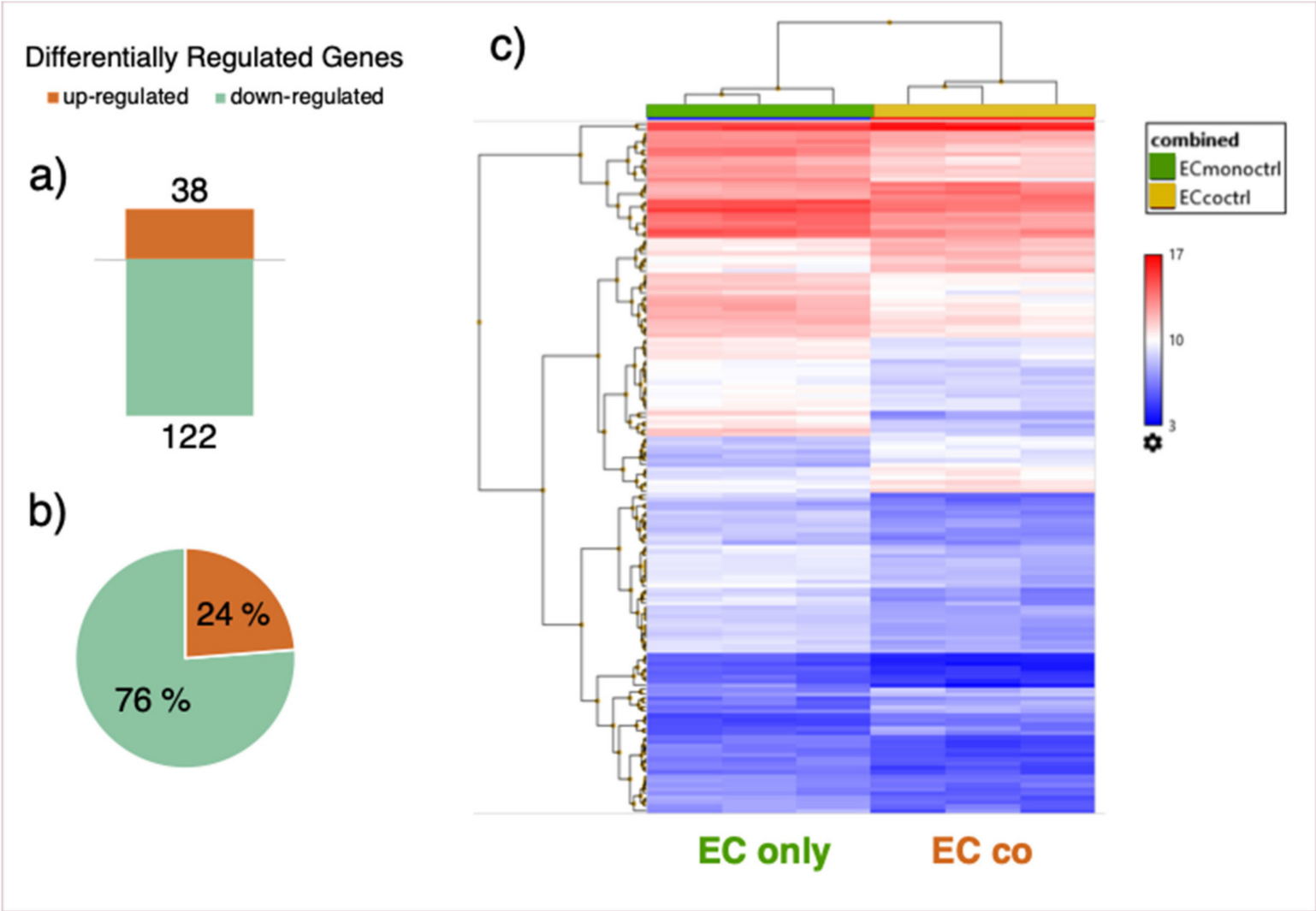

Figure 6. Differentially regulated genes (DRGs). Number of DRGs in co-cultured vs. mono-cultured endothelial cells (ECs). A total of 38 genes were upregulated, while 122 genes were downregulated (a). Pie chart representation of the same data as in (a) denoting up-and downregulated genes in\% of total number of DRGs (b). Heat map representation of DRGs (c). Comparison of gene expression data in co-cultures vs. mono-cultured ECs was performed by using Transcriptome Analysis Console (TAC, Applied Biosystems). For the analysis, a fold change (FC) cut-off of $1.5(\log 2 \mathrm{FC} \pm 0.59)$ and an FDR p-value of 0.05 were applied.

Pathway enrichment analysis on DRGs revealed a major impact of co-culture on extra cellular matrix (ECM) regulation as well as on changes of inflammatory pathways (Table 1).

Table 1. Pathway enrichment analysis of differentially regulated genes (DRGs) between endothelial cell co-cultures and monocultures.

\begin{tabular}{ccc}
\hline Pathway & Overlap & Adj. $\boldsymbol{p}$-Value \\
\hline TGF-beta regulation of extracellular matrix & $40 / 565$ & $9.37 \mathrm{E}-23$ \\
Interleukin-1 regulation of extracellular matrix & $16 / 120$ & $2.98 \mathrm{E}-12$ \\
Gastrin pathway & $9 / 44$ & $4.41 \mathrm{E}-08$ \\
TNF-alpha effects on cytokine activity, cell motility, and apoptosis & $12 / 135$ & $5.55 \mathrm{E}-07$ \\
Interleukin-5 regulation of apoptosis & $12 / 144$ & $9.32 \mathrm{E}-07$ \\
Interleukin-2 signaling pathway & $26 / 847$ & $2.30 \mathrm{E}-06$ \\
Immune system signaling by interferons, interleukins, prolactin, and growth hormones & $15 / 280$ & $3.02 \mathrm{E}-06$ \\
Fos-related antigen (FRA) pathway & $7 / 37$ & $3.93 \mathrm{E}-06$ \\
Oncostatin M & $14 / 311$ & $6.16 \mathrm{E}-05$ \\
Interferon alpha/beta signaling & $7 / 64$ & $1.57 \mathrm{E}-04$ \\
Interferon signaling & $10 / 168$ & $2.09 \mathrm{E}-04$ \\
Fibroblast growth factor 1 & $5 / 26$ & $2.75 \mathrm{E}-04$ \\
T cell receptor regulation of apoptosis & $18 / 603$ & $3.63 \mathrm{E}-04$ \\
Thymic stromal lymphopoietin (TSLP) pathway & $7 / 90$ & 0.00112 \\
Cytokine-cytokine receptor interaction & $6 / 60$ & 0.00107 \\
Hypertrophy pathway & $11 / 265$ & 0.00138
\end{tabular}


Table 1. Cont.

\begin{tabular}{|c|c|c|}
\hline Pathway & Overlap & Adj. $p$-Value \\
\hline Activator protein 1 (AP-1) transcription factor network & $6 / 70$ & 0.00219 \\
\hline Epidermal growth factor receptor 1 (EGFR1) pathway & $8 / 152$ & 0.00336 \\
\hline Cytosolic tRNA aminoacylation & $4 / 24$ & 0.00330 \\
\hline Type II interferon signaling (interferon-gamma) & $5 / 50$ & 0.00430 \\
\hline Ataxia-telangiectasia mutated (ATM)-dependent DNA damage response & $6 / 82$ & 0.00441 \\
\hline TNF-like weak inducer of apoptosis (TWEAK) regulation of gene expression & $4 / 27$ & 0.00465 \\
\hline Follicle-stimulating hormone $(\mathrm{FSH})$ regulation of apoptosis & $10 / 263$ & 0.00475 \\
\hline Folate metabolism & $5 / 63$ & 0.0110 \\
\hline
\end{tabular}

Analysis was performed using NCATS BioPlanet on the Enrichr website. Second column describes number of regulated genes compared to total number of genes in the pathway and the $p$-value adjusted for multiple testing is noted in the last column. DRGs were determined based on a fold change (FC) cut-off of $1.5(\log 2 \mathrm{FC} \pm 0.59)$ and an FDR $p$-value of 0.05 .

Possible influential DRGs with regard to barrier function based on literature search are shown in Table 2 . The list includes several pro-inflammatory cytokines like IL-1- $\alpha$, IL-1- $\beta$, IL-32 and chemokine ligands-5, -6, -8 and -10 as well as VEGF-C, which are all transcriptionally downregulated in co-cultured cells. Other soluble factors regulated in co-cultured ECs comprise TGF- $\beta 2$, the NOTCH ligand jagged-1 as well as BMP-4 and BMP-6. When looking at known junctional proteins, we found occludin and claudin-1 to be downregulated significantly on the transcriptional level upon co-culture. Furthermore, cell membrane receptors for leptin and lysophosphatidic acid are up- and downregulated, respectively. Additionally, co-cultured cells differentially express many ECM constituents, several of which are TGF- $\beta$-regulated, such as latent TGF- $\beta$ binding protein 1 , serpins, biglycan and tissue plasminogen activator.

Table 2. List of differentially regulated genes (DRGs) potentially linked to barrier function [23-27].

\begin{tabular}{|c|c|c|c|}
\hline Gene & Gene Description & $\begin{array}{c}\log 2 \mathrm{FC} \\
\text { (co- vs. } \\
\text { Monoculture) }\end{array}$ & $\begin{array}{c}\text { FDR } \\
p \text {-Value }\end{array}$ \\
\hline \multicolumn{4}{|c|}{ Soluble mediators } \\
\hline CXCL8 & Chemokine (C-X-C motif) ligand 8 & -3.7 & $1.68 \mathrm{E}-07$ \\
\hline CXCL5 & Chemokine (C-X-C motif) ligand 5 & -2.2 & 0.0009 \\
\hline CXCL6 & Chemokine (C-X-C motif) ligand 6 & -1.9 & 0.036 \\
\hline CXCL10 & Chemokine (C-X-C motif) ligand 10 & -1.5 & 0.0045 \\
\hline IL1B & Interleukin 1 beta & -2.4 & 0.0003 \\
\hline IL1A & Interleukin 1 alpha & -1.4 & 0.0021 \\
\hline IL32 & Interleukin-32 & -1.7 & 0.0002 \\
\hline VEGFC & Vascular endothelial growth factor C & -1.3 & 0.0016 \\
\hline TGFB2 & Transforming growth factor beta 2 & 1.1 & 0.016 \\
\hline BMP4 & Bone morphogenetic protein 4 & 1.5 & 0.0048 \\
\hline BMP6 & Bone morphogenetic protein 6 & 1.4 & 0.0021 \\
\hline \multicolumn{4}{|c|}{ Junctional Proteins } \\
\hline CLDN1 & Claudin-1 & -2.0 & 4.69E-05 \\
\hline OCCL & Occludin & -1.1 & 0.034 \\
\hline \multicolumn{4}{|l|}{ ECM Proteins } \\
\hline ADAMTS6 & $\begin{array}{l}\text { ADAM metallopeptidase with } \\
\text { thrombospondin type } 1 \text { motif } 6\end{array}$ & -1.3 & 0.0008 \\
\hline LAMB3 & Laminin beta 3 & -1.9 & 0.0008 \\
\hline SERPINE1 & $\begin{array}{l}\text { Serpin peptidase inhibitor, calde E } \\
\text { (nexin, plasminogen activator } \\
\text { inhibitor, type } 1 \text { ) }\end{array}$ & -1.6 & 0.0012 \\
\hline PLAU & Plasminogen activator, urokinase & -1.5 & 0.0019 \\
\hline
\end{tabular}


Table 2. Cont.

\begin{tabular}{|c|c|c|c|}
\hline Gene & Gene Description & $\begin{array}{c}\log 2 \text { FC } \\
\text { (co- vs. } \\
\text { Monoculture) }\end{array}$ & $\begin{array}{c}\text { FDR } \\
p \text {-Value }\end{array}$ \\
\hline LTBP1 & $\begin{array}{l}\text { Latent transforming growth factor } \\
\text { beta binding protein } 1\end{array}$ & -1.1 & 0.0022 \\
\hline EFEMP1 & $\begin{array}{l}\text { EGF containing fibulin-like ECM } \\
\text { protein1 }\end{array}$ & 0.86 & 0.0125 \\
\hline SERPINA3 & $\begin{array}{l}\text { Serpin peptidase inhibitor, calde A } \\
\text { (alpha-1 antiproteinase, antitrypsin) }\end{array}$ & 1.6 & 0.0252 \\
\hline BGN & Biglycan & 1.5 & 0.0348 \\
\hline \multicolumn{4}{|c|}{ Cell surface proteins } \\
\hline JAG1 & Jagged 1 & -1.2 & 0.020 \\
\hline LPAR1 & Lysophosphatidic acid receptor 1 & -1.3 & 0.0009 \\
\hline LEPR & Leptin receptor & 1.1 & 0.0092 \\
\hline
\end{tabular}

To validate some of our gene expression results also on the protein level (Supplementary Figure S10), we performed a membrane-based antibody array. Since we observed a high number of DRGs related to inflammation, we decided to use the Proteome Profiler Human XL Cytokine Array Kit, which detects the expression of 105 proteins. This membrane-based antibody array detects the relative protein expression levels by means of chemiluminescence, therefore, we used two different exposure times ( $3 \mathrm{~min}$ and $25 \mathrm{~min}$ ) to capture more and less abundantly expressed proteins. Among the highly expressed proteins, co-culture does not seem to induce big changes, with the only exception of epidermal growth factor (EGF), which was downregulated by $81 \%$ (Figure $7 \mathrm{a}$ and Table 3). However, regulated proteins detected following prolonged exposure include different cytokines (IL-1- $\alpha$, IL-1- $\beta$, IL-3) and chemokines of the CXC-motif ligands CXCL1, CXCL5, CXCL10, CXCL11, CXCL12, CXCL8 (Figure 7c,d; Table 3). In EC-PC co-cultures, a strong modulation in IL binding proteins was observed with decrease of $100 \%$ in IL-18-BP and an increase of $83 \%$ in IL-1-R4 (Figure 7d and Table 3). Interestingly, in co-cultured cells hepatocyte growth factor (HGF) increased by $164 \%$ and PDGF-AB/-BB by $31 \%$. We also observed a $44-50 \%$ decrease in expression of granulocyte-macrophage colony-stimulating factor (CSF-2 and CSF-3) and kallikrein-3. Results are also depicted in Table 3, together with a color-code denoting if the detected protein expression levels correspond with the mRNA levels detected by the microarray.

Table 3. List of differentially expressed proteins using a cytokine proteome array.

\begin{tabular}{cccc}
\hline Protein & Array Coordinates & Protein Regulation & mRNA Regulation \\
\hline CXCL1 & D1 & $-55 \%$ & down $(\mathrm{ns})$ \\
CXCL5 & C2 & $-34 \%$ & down \\
CXCL8 & E4 & $-25 \%$ & down \\
CXCL10 & F10 & $-61 \%$ & down \\
CXCL11 & F11 & $-59 \%$ & $\mathrm{nr}$ \\
CXCL12 & H12 & $-31 \%$ & up $(\mathrm{ns})$ \\
IL-1-a & D8 & $-64 \%$ & down \\
IL-1-b & D & $-34 \%$ & down \\
IL-1-Ra & D10 & $-50 \%$ & $\mathrm{nr}$ \\
IL-1-R4 & I3 & $+83 \%$ & $\mathrm{up}$ \\
IL-3 & D12 & $-100 \%$ & $\mathrm{nr}$ \\
IL-18-BP & E12 & $-100 \%$ & $\mathrm{nr}$ \\
PDGF-AB/-BB & H4 & $+31 \%$ & $\mathrm{nr}$ \\
HGF & D3 & $+164 \%$ & $\mathrm{nr}$ \\
MIC-1 & C10 & $-47 \%$ & $\mathrm{nr}$ \\
\hline
\end{tabular}


Table 3. Cont.

\begin{tabular}{cccc}
\hline Protein & Array Coordinates & Protein Regulation & mRNA Regulation \\
\hline CSF-2 & C11 & $-46 \%$ & $\mathrm{nr}$ \\
CSF-3 & C9 & $-44 \%$ & $\mathrm{nr}$ \\
Kallikrein 3 & F12 & $-53 \%$ & $\mathrm{nr}$ \\
PECAM1 (CD31) & $\mathrm{J} 4$ & $+14 \%$ & $\mathrm{nr}$ \\
SERPIN E1 & $\mathrm{I} 1$ & $+16 \%$ & $\mathrm{down}$ \\
Pentraxin & $\mathrm{H} 5$ & $-27 \%$ & $\mathrm{down}$ \\
EGF & $\mathrm{B} 10$ & $-81 \%$ & $\mathrm{nr}$ \\
Endoglin & C3 & $+10 \%$ & $\mathrm{up}(\mathrm{ns})$ \\
PLAUR & I10 & $-11 \%$ & down $(\mathrm{ns})$ \\
DPPIV & B9 & $-17 \%$ & $\mathrm{nr}$ \\
ICAM-1 & D4 & $+16 \%$ & $\mathrm{nr}$ \\
MIF & G7 & $+20 \%$ & $\mathrm{nr}$ \\
Emmprin & B11 & $+7 \%$ & $\mathrm{nr}$ \\
\hline
\end{tabular}

List of differentially expressed proteins using a cytokine proteome array (membrane-based, chemiluminescent detection). Array coordinates are shown in the second column for localization of spots in Figure $7 \mathrm{~b}, \mathrm{~d}$. Column 3 denotes the observed change in protein expression in co-cultures in relation to protein levels in mono-cultures. Analysis was performed with the image processing software ImageJ (including background subtraction). The last column denotes regulation of the corresponding mRNA levels upon co-culture, as was determined by the microarray (upregulated (up); downregulated (down); not regulated (nr); ns: non-significantly with a $p$ value $<0.05$, but FDR $p$-value $>0.05$ ). Matching transcriptomic and proteomic results are color-coded in green, opposing results are highlighted in orange.

a)

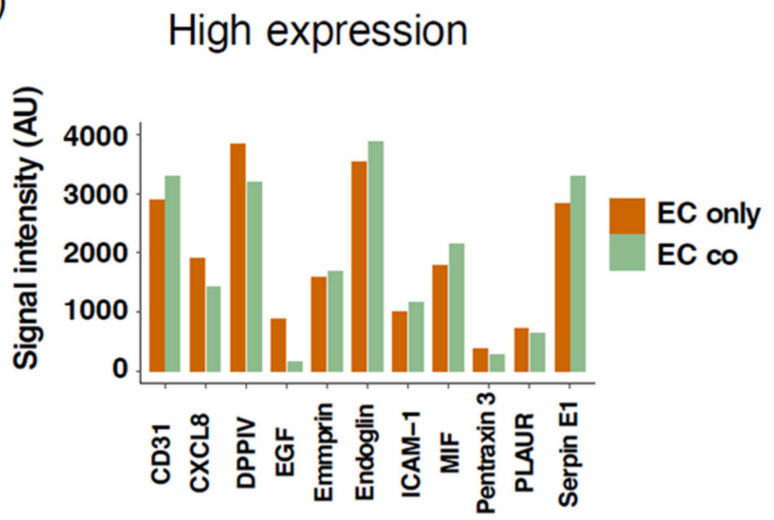

b)

EC only
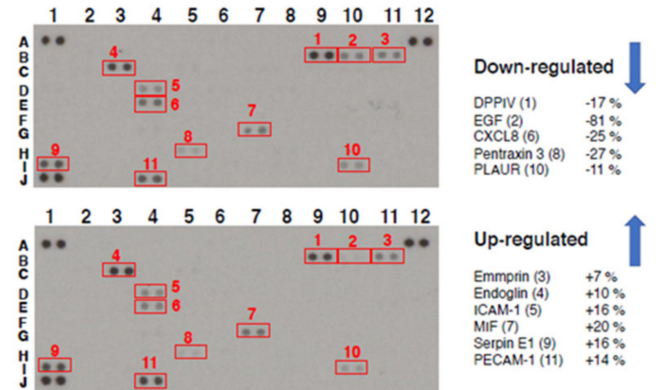

c)

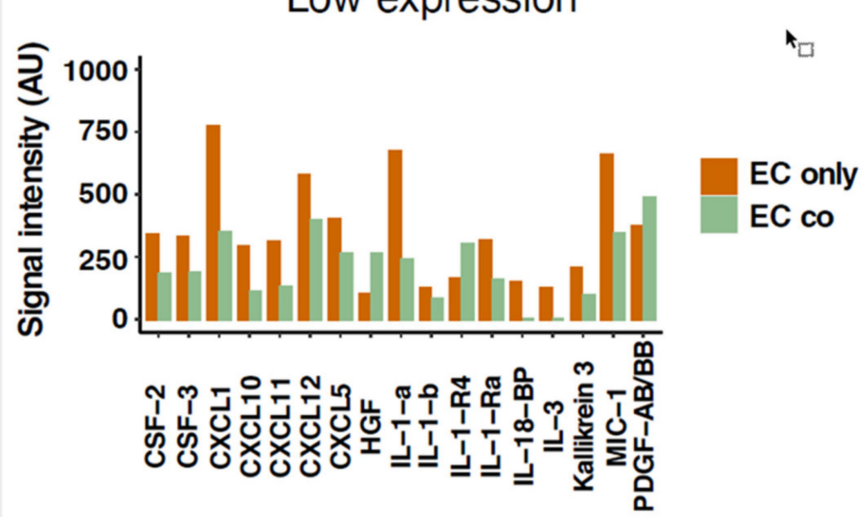

d)

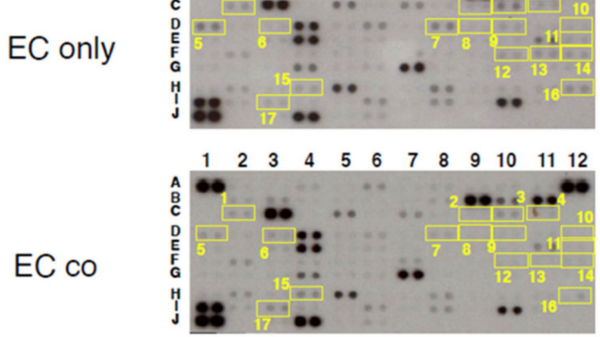

Figure 7. Differential expression of several cytokines in mono- and co-cultured endothelial cells (ECs). Proteome analysis has been performed using the Proteome Profiler Human XL Cytokine Array Kit using equal amounts of cell lysates from ECs cultured alone (EC only) and in co-cultures with pericytes (EC co). Representative array blots are shown after a short exposure time of $3 \mathrm{~min}(\mathbf{b})$ and after long exposure time of $25 \mathrm{~min}(\mathbf{d})$. Bar graphs show the average signal intensities of the framed spots on the array blots and include measurements of two independent experiments at high (a) and low (c) exposure times, respectively. The legends on the right of the array blots denote the proteins as numbered in the respective blots. Analysis was performed with the image processing software ImageJ (including background subtraction). Experiment was performed twice with independent samples. 


\section{Discussion}

In this study, we present a fully human in vitro model for the blood brain barrier (BBB) by co-culturing the cerebral microvascular endothelial cell line (hCMEC/D3) with primary brain vascular pericytes (hBVP) grown on opposite sides of a porous transwell membrane to maintain basolateral contact through the $0.4 \mu \mathrm{m}$ pores. Studies with co-culture models often make use of pure animal or a mixture of animal and human cell types, which may be of a poor predictive value for translation into human physiology $[28,29]$. It is essential to understand the mechanism of barrier function in fully human models of the BBB as there are key differences in the morphology and function between animal and human cells in the brain [29]. Although cell-cell junctional units are complex, the 2D EC-PC model used provides a simple and inexpensive setup to explore the relative contribution of single cell types in regulating BBB function $[9,29]$. More recently, complex 3D models and spheroids with human induced pluripotent stem cells have been developed [22,28,29]. However, spheroids do not allow for TEER measurements, and the assembly of such models is expensive and complex.

The observed increase of barrier function in endothelial cells (ECs) cultured with pericytes (PCs) on the opposing side of a transwell insert is in agreement with several previous studies $[11,12,21,30]$. The fact that the permeability to higher molecular weight dextrans $(40 \mathrm{kDa})$ is decreased in presence of PCs indicates that trans-cellular transport pathways are affected in our co-culture model as such large molecules most probably travers the endothelium via non-specific transcytosis [31]. This observation is in agreement with a previous study showing increased trans-cellular pathways in pericyte-deficient mice [1,2]. The observed increase in TEER and the decreased permeability to $4 \mathrm{kDa}$ dextrans further imply that PCs affect para-cellular transport of ECs by potentially inducing and/or maintaining the function of junctional complexes between neighboring cells $[32,33]$. Given the small hydrodynamic radius of $4 \mathrm{kDa}$ FITC dextran of $1.4 \mathrm{~nm}$, passage of this tracer via the paracellular pathway is feasible [34]. In addition, even though transporters and channels in the cell membrane also affect the ohmic resistance of a cell layer, at low frequency measurements the contribution of cellular junctions predominates, which infers that cellZcope measurements largely reflect paracellular transport characteristics [35].

Our findings on EC-barrier function using the cellZcope instrument were comparable to those observed using xCELLigence ECIS system, which allows overall assessment of various aspects of cell behavior including adhesion and barrier strength in EC monolayers grown directly on gold-plated electrodes. The xCELLigence electrodes can measure acute temporal changes in barrier resistance across EC monolayer as well as paracellular and basolateral resistance and is more sensitive for assessing barrier function in cell lines [36]. However, the xCELLigence system does not allow the co-culture of cells with basolateral contact for barrier integrity measurements, as was possible with cellZcope.

To better understand the mechanisms involved in the strengthening of endothelial barrier function by PCs, we performed gene expression analysis on co- and mono-cultured ECs. To the best of our knowledge, this is the first study comparing the transcriptomic profile of ECs cultured alone and ECs co-cultured with PCs on the opposite side of a transwell insert with basolateral surface of both cells in direct contact with each other. In a previous transcriptomic study in ECs, the ECs and PCs are co-cultured in a non-contact model (EC's on membrane and PCs on the culture well surface), thus allowing only contact with soluble factors [37].

\subsection{Effect of Co-Culture on Inflammatory Profile of ECS}

In the present study, the most striking change observed in the transcriptomic analysis was the downregulation of several inflammatory cytokines in ECs co-cultured with PCs compared to EC monocultures. This was also highly reflected in the results from pathway analysis, with a great number of regulated pathways in co-cultured cells related to inflammation. This includes obvious inflammatory pathways induced by inflammatory mediators like interferons, interleukins or TNF- $\alpha$, but also receptor of advanced glycation 
end products- (RAGE-) and FOS-related antigen- (FRA-) pathways comprise an inflammatory component $[38,39]$. Apart from the so-called homeostatic cytokines (such as CXCL12, CCL20 or XC3XL), which are expressed at normal or even high levels under physiologic conditions [40], pro-inflammatory cytokines are secreted at high concentrations in response to different inflammatory stimuli and have been shown to exert negative effects on the BBB $[24,41,42]$. In the present study, the decreased pro-inflammatory profile of ECs cocultured with PCs is one possible reason for improved barrier function in co-cultures [24]. The fact that most of the transcriptionally regulated cytokine mRNAs also show a corresponding trend in the protein expression highlights the significance of the observed changes. It further confirms the reliability of our microarray data by demonstrating that the transcriptional regulation also triggers changes in corresponding protein levels. Compared to most other cytokines, we did not observe congruent changes in gene and protein expression of CXCL12, which may be due to posttranscriptional regulation commonly observed in cytokines [43]. Our results indicate that co-culture with PCs contributes to maintaining a low inflammatory profile by downregulation of several pro-inflammatory cytokines on the transcriptional as well as on the protein level.

The above notion is further supported by the fact that many different interleukins and chemokine CXC-motif ligands, which are upregulated following ultrasound and infection induced barrier disruption [23,42,44], were downregulated in ECs co-cultured with PCs. Moreover, in co-cultured ECs, we observed a decrease in IL-18-binding protein and an increase in IL-1-R4. Since IL-18 is protective against BBB-disruption [45], a decrease in IL-18-BP would increase IL-18 availability and result in increased protective actions on the BBB. With regard to IL-1-R4 (also called ST2), which is a decoy receptor for IL-33 and blocks its function [46,47], upregulation in its expression may protect BBB against IL-33 mediated EC insult, activation and microglia-mediated neuroinflammation. We also observed a decrease in expression of granulocyte-macrophage colony-stimulating factors (CSF-2 and CSF-3) and kallikrein-3, three key inflammatory players [48,49]. Both CSFs and kallikrein-3 are known to negatively influence BBB dynamics and integrity; hence their downregulation in ECs co-cultured with PCs would reflect their protective role in maintaining EC integrity.

\subsection{Soluble Mediators and Cell Surface Proteins}

In ECs co-cultured with PCs, hepatocyte growth factor (HGF) increased by $164 \%$, platelet-derived growth factor-AB/-BB (PDGF-AB/-BB) by 31\%, whereas EGF was decreased by $81 \%$. Since HGF and PDGF-AA/-BB have been shown to improve BBB integrity and function [50,51], whereas EGF increases BBB permeability [52], the PC induced changes reflect improvement in EC barrier. Different soluble factors, including PDGF-B, vascular endothelial growth factor (VEGF), transforming growth factor beta (TGF- $\beta$ ), basic fibroblast growth factor (FGF-2) and angiopoietin 1 and 2, have been shown to contribute significantly to the paracrine signaling between ECs and PCs [51]. The importance of PDGF-B with regard to EC-PC interaction has been demonstrated in numerous in vitro as well as in vivo studies [51]. Our observation of increased PDGF-AB/-BB protein expression in co-cultured ECs is in line with the relevance of this growth factor in EC-PC crosstalk. VEGF, a potent stimulator of angiogenesis under physiological but also pathological conditions [53], is a well-known inducer of vascular permeability at high concentrations [54,55]. The observed decrease of VEGF-C, but no change in VEGF-A and VEGF-B expression in co-cultured ECs, therefore, depicts a possible mechanism for barrier induction in co-culture, by reducing autocrine BBB disruption. Interestingly, it has been observed that VEGF-C/VEGFR2 signaling in PCs leads to vessel destabilization by antagonizing PDGFR- $\beta$ signaling and depleting PC coverage of the blood vessels [56], which presents another potential explanation on how downregulation of VEGF-C could have beneficial effects on endothelial barrier.

The reduced expression of VEGF-C might also be linked to the downregulation of the cellular receptor for lysophosphatidic acid (LPAR1), as LPAR1 is known to mediate VEGF-C induction by LPA, thereby promoting angiogenesis [57]. The impact of LPA on BBB is controversial and thought to be tissue-dependent [58]. However, in vitro and in vivo 
experiments clearly show that LPA signaling diminishes BBB function [25]. The reduced expression of LPAR1 in co-cultured ECs might therefore also contribute to the barrier improving effects by suppressing angiogenic activities of ECs. Another cell surface protein that is downregulated in EC co-cultures on mRNA as well as protein level (Supplementary Figure S12) is the NOTCH ligand Jagged 1. Our finding is further supported by Kang et al. [14], who observed downregulation of Jagged 1 on the protein level in ECs co-culture with PCs in the same model as we used in the present study (indirect EC-PC co-culture with contact through a permeable membrane). NOTCH $1 /$ Jagged 1 signaling is involved in juxtacrine communication between ECs and mural cells and plays an important role during vascular development [59], whereas increased Jagged 1 levels in vessels are linked to barrier disruption via NOTCH and VE-cadherin/beta-catenin signaling [27]. Additionally, the well-established barrier disrupter TNF- $\alpha$ upregulates Jagged 1 expression [14]. A cellular receptor potentially supporting barrier function in our co-culture model is leptin receptor (LEPR). Deficiency in leptin receptor induces BBB dysfunction in mice [26]. Hence, the observed decrease in Jagged 1/increase in LEPR expression in EC co-cultured with PC may contribute to the improved barrier function in our model.

\subsection{Extracellular Matrix Regulation}

The high impact of PC-EC co-culture on the regulation of ECM proteins is apparent from the pathway analysis results, as the two most significantly enriched pathways are linked to regulation of ECM. This could explain why the positive effect of co-culture is not mimicked by basolateral treatment with PC conditioned media (PCM), since immediate contact of the two cell types and the interaction with their extracellular environment is required. This contention is supported by the findings by Hartmann et al. who demonstrated that ECs cultured on pericyte-derived ECM form a tighter barrier than when cultured on their own matrix [60]. Reinforcing this hypothesis, connexin 43, a major gap junction protein that is known to be involved in the formation of direct contacts between ECs and PCs [61,62], is upregulated in PC co-cultures (unpublished data). Connexin 43 has been shown to play an important role in barrier function by co-localizing with TJ proteins, and the deletion of this protein results in severe barrier dysfunction $[63,64]$.

Transforming growth factor beta (TGF- $\beta$ ) signaling is highly regulated upon coculture, as is evident from the pathway enrichment analysis, showing the most significantly regulated pathway to be 'TGF- $\beta$ regulation of $\mathrm{ECM}^{\prime}$ '. We also observed favorable changes in PECAM-1/CD31, SERPIN E1/PAI-1, Endoglin, PLAUR/uPAR/CD87, all TGF- $\beta$ associated factors known to preserve EC barrier function. TGF- $\beta$ superfamily ligands are a versatile group of different secreted factors including bone morphogenetic proteins (BMPs), activins, inhibins, nodals as well as growth and differentiation factors [65]. They control several aspects in the developing organism and play an important role in tissue homeostasis in the adults by regulating different function such as cell proliferation, differentiation as well as ECM production. Hence, TGF- $\beta$ signaling strongly depends on spatial and temporal expression profiles of all involved signaling constituents, which renders a highly complex regulatory system. Several target proteins of the TGF- $\beta$ pathway include ECM proteins, which are themselves implicated in TGF- $\beta$ regulation, mainly by activating latent forms of TGF- $\beta$ subtypes [66]. Due to the complex nature of TGF- $\beta$ signaling, a thorough analysis of regulated proteins involved in this pathway is beyond the scope of this study.

\subsection{Junctional Proteins}

In ECs co-cultured with PCs, we observed no change in claudin-5 or Zonula occludens proteins (ZO-1 to 3), but a decrease in occludin and claudin-1 gene expression, compared to ECs alone. Moreover, we observed a decrease in claudin-5 protein expression (Supplementary Figure S13). Junctional proteins, such as claudin-5 and occludin, play a critical role in regulating BBB permeability. However, increasing evidence suggests that BBB permeability can be influenced by junctional protein-independent mechanisms. In Claudin5 knock out mice, the size-selective loosening of $\mathrm{BBB}$ is observed with change in $\mathrm{BBB}$ 
morphology [67]. Reduced barrier function under hypoxic conditions is induced by TJ rearrangement, while the protein expression remained stable or even increased slightly, however non-significantly [68]. Similarly, BBB damage in the early phase of ischemic stroke leads to a claudin- 5 re-localization, but no change in overall protein levels is observed [69]. Interestingly, claudin-1 dependent destabilization of BBB has been observed in chronic stroke [70]. Moreover, claudin- 1 can interfere with claudin- 5 as its appearance in tight junction complex reduces claudin- 5 strands and claudin-5/ZO- 1 interaction, thereby limiting its incorporation in tight junction complex [70]. Hence the finding of decreased claudin-1 in ECs co-cultured with PCs would positively influence EC barrier. Taken together, these findings support the notion that bare TJ protein expression levels do not always meaningfully reflect barrier integrity, neither on the mRNA nor on the protein level. Notably higher consideration should be attributed to post-translational modifications like phosphorylation status, molecular interactions and cellular localization of TJ proteins $[68,69,71]$.

\subsection{Effects of Pericyte Conditioned Media (PCM) on Endothelial Barrier Function}

Crosstalk between ECs and PCs depends on paracrine signaling as well as direct cell-cell interactions. Different studies showed positive effects of PC-conditioned media (PCM) on EC barrier function [12,72]. Our results from PCM experiments, however, indicated no change in barrier properties of EC monolayers by PC-released soluble factors (Supplementary Figure S5). We further used PCM from co- and mono-cultured PCs and did not observe any differential effects between co- and mono-cultured PCM. Potential explanation(s) for the lack of barrier improving effects of PCM on EC function can only be speculated upon. It is feasible that PC-derived factors are present in high concentration gradient between EC-PC basolateral interface. Moreover, active contribution of endoplasmic vesicles in facilitating PC-EC communication and differences in factors generated from apical and basolateral cell surface cannot be ruled out.

Differential expression of several transporters, channels and lipids on the luminal and abluminal side is a well-known feature of ECs and plays an important role in BBB integrity [73]. Various soluble factors have been shown to induce polarized signaling, such as VEGF, histamine, LPA, TGF- $\beta$ and LPC [74]. The observed differential effects of PCM on the apical and basolateral surface of an endothelial monolayer regarding barrier function can be explained by this apicobasal polarity of ECs. Whereas basolateral PCM treatment did not significantly change barrier function of an already established EC monolayer, it had demolishing effects if applied apically. The fact that conditioned media from SMCs showed similar deteriorating effects leads to the conclusion that the observed effect is not specific to PCs but might rather be explained by the presence of apicobasal polarity of ECs. Similarly, when PCM was applied basolaterally to growing EC monolayer, where the barrier was not yet formed and soluble factors could pass through the permeable transwell membrane, thereby acting on the apical side of ECs, a decrease in TEER was observed. This was accompanied by an increase in permeability to low molecular weight dextran $(4 \mathrm{kDa})$. Both of these results represent an effect on paracellular rather than transcellular permeability (see above). Taken together, these observations from PCM experiments indicate that soluble mediators secreted by PCs seem to play a subordinate role in the process of para-cellular barrier improvement in our model.

The non-contact co-culture model with PCs grown on the well-plate surface while ECs were cultured in the transwell insert resulted in a decrease in barrier function when compared to an EC monolayer. This experimental set-up reflects the situation of prolonged PCM treatment resulting in decreased barrier function. Hatherell et al. [30] observed a comparable effect by investigating different configurations of co-culture models including ECs, PCs and also astrocytes (ACs). While culturing ECs and PCs together in the indirect co-culture model on a porous membrane increased barrier function, the addition of PCs to the well surface of an EC-AC co-culture led to a significant drop in the measured TEER. Unfortunately, no data with ECs and PCs alone was shown in the non-contact model used. These results are in contrast to other studies, which observed improved barrier properties in 
the non-contact co-culture model or after PCM treatment [10,11,75]. A potential explanation for the different outcomes may be differences in experimental setup and/or the use of cells from different species.

In the past, the oversimplified and non-physiological model obtained by simply combining PCs and ECs as co-cultures has been used [76-78]. Our finding of a reduced barrier function in this direct PC-EC co-culture is a clear indication for the non-physiologic nature of this model. The same effect has also been observed by another in vitro study performed with iPSC-derived pericytes [22]. By fluorescent imaging, they further showed that PCs outcompete ECs for covering the glass surface, such that ECs are forced to overgrow PCs, which most probably leads to barrier deterioration.

In conclusion, our results provide first evidence that in human EC-PC co-cultures, contact on the basolateral surface represents a physiological orientation that is responsible for increased EC barrier function. PCs regulate EC barrier function on the para- as well as transcellular level. Transcriptomic analysis of genes and cytokine proteome arrays support our findings from in vitro barrier studies and highlight that PC induced EC barrier function is associated with decrease in pro-inflammatory cytokine profile, regulation of TGF- $\beta$ as well as extracellular matrix pathways and multiple permeability improving soluble factors, but not tight junction proteins. Using human PC-EC co-cultures with basolateral contacts may serve as a viable in vitro model for investigating BBB pathophysiology in inflammatory and neurodegenerative disease, as well as for therapeutic drug delivery studies.

Supplementary Materials: The following are available online at https:/ / www.mdpi.com/article/10 $.3390 /$ cells10040963/s1, Supplementary Figure S2: Measuring barrier function with the xCELLigence system, Supplementary Figure S2: Effect of pericyte (PC) cell number on improvement of barrier function; Supplementary S3: Real-time TEER measurement of mono- and co-cultures of endothelial cells (ECs) and pericytes (PCs); Supplementary Figure S4: Addition of pericytes (PCs) to an established endothelial (EC) monolayer; Supplementary Figure S5: Effect of basolateral pericyte-conditioned media (PCM) on endothelial barrier function; Supplementary Figure S6: Effect of non-contact co-culture on barrier function; Supplementary Figure S7: Conditioned media from co-cultured and mono-cultured pericytes (PCs); Supplementary Figure S8: Measurements of endothelial barrier function after apical treatment with conditioned media from smooth muscle cells (SMC-CM); Supplementary Figure S9: Effect of pericyte conditioned media (PCM) on cell viability; Supplementary Figure S10: Workflow of sample collection for the microarray and proteome array; Supplementary Figure S11: Principle Component Analysis (PCA); Supplementary Figure S12: Jagged-1 expression in co-culture endothelial cells (ECs); Supplementary Figure S13: Claudin-5 expression decreases in co-culture endothelial cells (ECs); Supplementary Table S1: Top ten upregulated genes in co-cultured endothelial cells.; Supplementary Table S2: Top ten downregulated genes in co-cultured endothelial cells

Author Contributions: Conceptualization, L.K. and R.K.D.; data curation, R.K.D.; formal analysis, L.K. and M.O.; funding acquisition, R.K.D.; investigation, L.K., O.O.O. and R.K.D.; methodology, L.K., M.O. and R.K.D.; project administration, B.I. and R.K.D.; resources, O.O.O., B.L., B.I. and R.K.D.; supervision, R.K.D.; validation, L.K. and M.O.; visualization, L.K.; writing-original draft, L.K., O.O.O., B.L., B.I. and R.K.D.; writing-review and editing, L.K., O.O.O., B.L., B.I. and R.K.D. All authors have read and agreed to the published version of the manuscript.

Funding: This research was funded by Swiss National Sciences Foundation 31003A-138067 (RKD); Uniscientia P100-2016 (RKD); SNF grant 31003A_170129 (OOO).

Institutional Review Board Statement: Not applicable.

Informed Consent Statement: Not applicable.

Data Availability Statement: All data supporting the findings of this study are available within the article and its supplemental data file or from the corresponding author upon reasonable request.

Acknowledgments: We thank Dipl. Biol. Margit Henry and Dipl. Biol. Tamara Rotshteyn from CMMC Gene Expression Affymetrix Facility, Cologne, Germany, for microarray assays, and PierreOlivier Couraud (Institute COCHIN, Paris, France) for providing human Cerebral Microvascular 
Endothelial Cell line (hCMEC/D3). This present work represents, in part, the PhD thesis work of L.K. conducted at University of Zurich.

Conflicts of Interest: The authors declare no conflict of interest. The funders had no role in the design of the study; in the collection, analyses or interpretation of data; in the writing of the manuscript or in the decision to publish the results. There are no conflicts of interest, which could be perceived as prejudicing the impartiality of the research reported.

\section{References}

1. Armulik, A.; Genove, G.; Mae, M.; Nisancioglu, M.H.; Wallgard, E.; Niaudet, C.; He, L.; Norlin, J.; Lindblom, P.; Strittmatter, K.; et al. Pericytes regulate the blood-brain barrier. Nature 2010, 468, 557-561. [CrossRef] [PubMed]

2. Daneman, R.; Zhou, L.; Kebede, A.A.; Barres, B.A. Pericytes are required for blood-brain barrier integrity during embryogenesis. Nature 2010, 468, 562-566. [CrossRef] [PubMed]

3. Lendahl, U.; Nilsson, P.; Betsholtz, C. Emerging links between cerebrovascular and neurodegenerative diseases-A special role for pericytes. EMBO Rep. 2019, 20, e48070. [CrossRef]

4. Zhang, Z.-S.; Zhou, H.-N.; He, S.-S.; Xue, M.-Y.; Li, T.; Liu, L.-M. Research advances in pericyte function and their roles in diseases. Chin. J. Traumatol. 2020, 23, 89-95. [CrossRef]

5. Komarova, Y.; Malik, A.B. Regulation of Endothelial Permeability via Paracellular and Transcellular Transport Pathways. Ann. Rev. Physiol. 2010, 72, 463-493. [CrossRef]

6. Tervonen, A.; Ihalainen, T.O.; Nymark, S.; Hyttinen, J. Structural dynamics of tight junctions modulate the properties of the epithelial barrier. PLoS ONE 2019, 14. [CrossRef]

7. Hervé, F.; Ghinea, N.; Scherrmann, J.-M. CNS Delivery Via Adsorptive Transcytosis. AAPS J. 2008, 10, 455-472. [CrossRef]

8. Patel, M.M.; Goyal, B.R.; Bhadada, S.V.; Bhatt, J.S.; Amin, A.F. Getting into the Brain. CNS Drugs 2009, 23, 35-58. [CrossRef] [PubMed]

9. Ogunshola, O.O. In Vitro Modeling of the Blood-Brain Barrier: Simplicity Versus Complexity. Curr. Pharm. Des. 2011, 17, 2755-2761. [CrossRef]

10. Hori, S.; Ohtsuki, S.; Hosoya, K.; Nakashima, E.; Terasaki, T. A pericyte-derived angiopoietin-1 multimeric complex induces occludin gene expression in brain capillary endothelial cells through Tie-2 activation in vitro. J. Neurochem. 2004, 89, 503-513. [CrossRef]

11. Dohgu, S.; Takata, F.; Yamauchi, A.; Nakagawa, S.; Egawa, T.; Naito, M.; Tsuruo, T.; Sawada, Y.; Niwa, M.; Kataoka, Y. Brain pericytes contribute to the induction and up-regulation of blood-brain barrier functions through transforming growth factor-beta production. Brain Res. 2005, 1038, 208-215. [CrossRef]

12. McGuire, P.G.; Rangasamy, S.; Maestas, J.; Das, A. Pericyte-Derived Sphinogosine 1-Phosphate Induces the Expression of Adhesion Proteins and Modulates the Retinal Endothelial Cell Barrier. Arterioscler. Thromb. Vasc. Biol. 2011, 31, e107-e115. [CrossRef] [PubMed]

13. Weksler, B.B.; Subileau, E.A.; Perrière, N.; Charneau, P.; Holloway, K.; Leveque, M.; Tricoire-Leignel, H.; Nicotra, A.; Bourdoulous, S.; Turowski, P.; et al. Blood-brain barrier-specific properties of a human adult brain endothelial cell line. FASEB J. 2005, 19, 1872-1874. [CrossRef] [PubMed]

14. Kang, T.-Y.; Bocci, F.; Jolly, M.K.; Levin, H.; Onuchic, J.N.; Levchenko, A. Pericytes enable effective angiogenesis in the presence of proinflammatory signals. Proc. Natl. Acad. Sci. USA 2019, 116, 23551-23561. [CrossRef] [PubMed]

15. Hamad, S.; Derichsweiler, D.; Papadopoulos, S.; Nguemo, F.; Saric, T.; Sachinidis, A.; Brockmeier, K.; Hescheler, J.; Boukens, B.J.; Pfannkuche, K. Generation of human induced pluripotent stem cell-derived cardiomyocytes in 2D monolayer and scalable 3D suspension bioreactor cultures with reduced batch-to-batch variations. Theranostics 2019, 9, 7222-7238. [CrossRef] [PubMed]

16. Huang, R.; Grishagin, I.; Wang, Y.; Zhao, T.; Greene, J.; Obenauer, J.C.; Ngan, D.; Dac-Trung, N.; Guha, R.; Jadhav, A.; et al. The NCATS BioPlanet-An Integrated Platform for Exploring the Universe of Cellular Signaling Pathways for Toxicology, Systems Biology, and Chemical Genomics. Front. Pharmacol. 2019, 10. [CrossRef] [PubMed]

17. Chen, X.L.; Nam, J.-O.; Jean, C.; Lawson, C.; Walsh, C.T.; Goka, E.; Lim, S.-T.; Tomar, A.; Tancioni, I.; Uryu, S.; et al. VEGF-Induced Vascular Permeability Is Mediated by FAK. Dev. Cell 2012, 22, 146-157. [CrossRef]

18. Schröder-Heurich, B.; Von Hardenberg, S.; Brodowski, L.; Kipke, B.; Meyer, N.; Borns, K.; Von Kaisenberg, C.S.; Brinkmann, H.; Claus, P.; Versen-Höynck, F. Vitamin D improves endothelial barrier integrity and counteracts inflammatory effects on endothelial progenitor cells. FASEB J. 2019, 33, 9142-9153. [CrossRef]

19. Jiang, W.; Chen, H.; Tai, Z.; Li, T.; Luo, L.; Tong, Z.; Zhu, W. Apigenin and Ethaverine Hydrochloride Enhance Retinal Vascular Barrier In Vitro and In Vivo. Transl. Vis. Sci. Technol. 2020, 9. [CrossRef]

20. Bednarek, R.; Selmi, A.; Wojkowska, D.; Karolczak, K.; Popielarski, M.; Stasiak, M.; Salifu, M.O.; Babinska, A.; Swiatkowska M. Functional inhibition of F11 receptor (F11R/junctional adhesion molecule-A/JAM-A) activity by a F11R-derived peptide in breast cancer and its microenvironment. Breast Cancer Res. Treat. 2020, 179, 325-335. [CrossRef]

21. Nakagawa, S.; Deli, M.A.; Kawaguchi, H.; Shimizudani, T.; Shimono, T.; Kittel, A.; Tanaka, K.; Niwa, M. A new blood-brain barrier model using primary rat brain endothelial cells, pericytes and astrocytes. Neurochem. Int. 2009, 54, 253-263. [CrossRef]

22. Jamieson, J.J.; Linville, R.M.; Ding, Y.Y.; Gerecht, S.; Searson, P.C. Role of iPSC-derived pericytes on barrier function of iPSCderived brain microvascular endothelial cells in 2D and 3D. Fluids Barriers CNS 2019, 16, 1-16. [CrossRef] 
23. Kovacs, Z.I.; Kim, S.; Jikaria, N.; Qureshi, F.; Milo, B.; Lewis, B.K.; Bresler, M.; Burks, S.R.; Frank, J.A. Disrupting the blood-brain barrier by focused ultrasound induces sterile inflammation. Proc. Natl. Acad. Sci. USA 2017, 114, E75-E84. [CrossRef] [PubMed]

24. Huang, X.; Hussain, B.; Chang, J. Peripheral inflammation and blood-brain barrier disruption: Effects and mechanisms. CNS Neurosci. Ther. 2021, 27, 36-47. [CrossRef]

25. Yu, Y.; Qin, J.; Liu, M.Z.; Ruan, Q.Y.; Li, Y.L.; Zhang, Z.H. Role of Rho kinase in lysophosphatidic acid-induced altering of blood-brain barrier permeability. Int. J. Mol. Med. 2014, 33, 661-669. [CrossRef]

26. Corem, N.; Anzi, S.; Gelb, S.; Ben-Zvi, A. Leptin receptor deficiency induces early, transient and hyperglycaemia-independent blood-brain barrier dysfunction. Sci. Rep. 2019, 9. [CrossRef]

27. Miloudi, K.; Oubaha, M.; Menard, C.; Dejda, A.; Guber, V.; Cagnone, G.; Wilson, A.M.; Tetreault, N.; Mawambo, G.; Binet, F.; et al. NOTCH1 signaling induces pathological vascular permeability in diabetic retinopathy. Proc. Natl. Acad. Sci. USA 2019, 116, 4538-4547. [CrossRef]

28. Le Roux, G.; Jarray, R.; Guyot, A.-C.; Pavoni, S.; Costa, N.; Theodoro, F.; Nassor, F.; Pruvost, A.; Tournier, N.; Kiyan, Y.; et al. Proof-of-Concept Study of Drug Brain Permeability between In Vivo Human Brain and an In Vitro iPSCs-Human Blood-Brain Barrier Model. Sci. Rep. 2019, 9. [CrossRef]

29. Stone, N.L.; England, T.J.; O'Sullivan, S.E. A Novel Transwell Blood Brain Barrier Model Using Primary Human Cells. Front. Cell. Neurosci. 2019, 13. [CrossRef]

30. Hatherell, K.; Couraud, P.-O.; Romero, I.A.; Weksler, B.; Pilkington, G.J. Development of a three-dimensional, all-human in vitro model of the blood-brain barrier using mono-, co-, and tri-cultivation Transwell models. J. Neurosci. Methods 2011, 199, 223-229. [CrossRef]

31. Klein, O.; Roded, A.; Hirschberg, K.; Fukuda, M.; Galli, S.J.; Sagi-Eisenberg, R. Imaging FITC-dextran as a Reporter for Regulated Exocytosis. J. Vis. Exp. 2018, e57936. [CrossRef]

32. Lai, C.H.; Kuo, K.H. The critical component to establish in vitro BBB model: Pericyte. Brain Res. Rev. 2005, 50, 258-265. [CrossRef]

33. Maherally, Z.; Fillmore, H.L.; Tan, S.L.; Tan, S.F.; Jassam, S.A.; Quack, F.I.; Hatherell, K.E.; Pilkington, G.J. Real-time acquisition of transendothelial electrical resistance in an all-human, in vitro, 3-dimensional, blood-brain barrier model exemplifies tight-junction integrity. FASEB J. 2018, 32, 168-182. [CrossRef]

34. Mobed-Miremadi, M.; Djomehri, S.; Keralapura, M.; McNeil, M. Fickian-Based Empirical Approach for Diffusivity Determination in Hollow Alginate-Based Microfibers Using 2D Fluorescence Microscopy and Comparison with Theoretical Predictions. Materials 2014, 7, 7670-7688. [CrossRef]

35. Cacopardo, L.; Costa, J.; Giusti, S.; Buoncompagni, L.; Meucci, S.; Corti, A.; Mattei, G.; Ahluwalia, A. Real-time cellular impedance monitoring and imaging of biological barriers in a dual-flow membrane bioreactor. Biosens. Bioelectron. 2019, 140, 145-153. [CrossRef]

36. Bischoff, I.; Hornburger, M.; Mayer, B.; Beyerle, A.; Wegener, J.; Furst, R. Pitfalls in assessing microvascular endothelial barrier function: Impedance-based devices versus the classic macromolecular tracer assay. Sci. Rep. 2016, 6. [CrossRef] [PubMed]

37. Heymans, M.; Figueiredo, R.; Dehouck, L.; Francisco, D.; Sano, Y.; Shimizu, F.; Kanda, T.; Bruggmann, R.; Engelhardt, B.; Winter, P.; et al. Contribution of brain pericytes in blood-brain barrier formation and maintenance: A transcriptomic study of cocultured human endothelial cells derived from hematopoietic stem cells. Fluids Barriers CNS 2020, 17, 1-28. [CrossRef] [PubMed]

38. Body-Malapel, M.; Djouina, M.; Waxin, C.; Langlois, A.; Gower-Rousseau, C.; Zerbib, P.; Schmidt, A.M.; Desreumaux, P.; Boulanger, E.; Vignal, C. The RAGE signaling pathway is involved in intestinal inflammation and represents a promising therapeutic target for Inflammatory Bowel Diseases. Mucosal Immunol. 2019, 12, 468-478. [CrossRef] [PubMed]

39. Birnhuber, A.; Biasin, V.; Schnoegl, D.; Marsh, L.M.; Kwapiszewska, G. Transcription factor Fra-2 and its emerging role in matrix deposition, proliferation and inflammation in chronic lung diseases. Cell. Signal. 2019, 64. [CrossRef] [PubMed]

40. Williams, J.L.; Holman, D.W.; Klein, R.S. Chemokines in the balance: Maintenance of homeostasis and protection at CNS barriers. Front. Cell. Neurosci. 2014, 8. [CrossRef]

41. Yu, M.; Ma, X.; Jiang, D.; Wang, L.; Zhan, Q.; Zhao, J. CXC chemokine ligand 5 (CXCL5) disrupted the permeability of human brain microvascular endothelial cells via regulating p38 signal. Microbiol. Immunol. 2020. [CrossRef]

42. Haarmann, A.; Schuhmann, M.K.; Silwedel, C.; Monoranu, C.-M.; Stoll, G.; Buttmann, M. Human Brain Endothelial CXCR2 Is Inflammation-Inducible and Mediates CXCL5-and CXCL8-Triggered Paraendothelial Barrier Breakdown. Int. J. Mol. Sci. 2019, 20. [CrossRef]

43. Kovarik, P.; Ebner, F.; Sedlyarov, V. Posttranscriptional regulation of cytokine expression. Cytokine 2017, 89, 21-26. [CrossRef]

44. Chai, Q.; He, W.Q.; Zhou, M.; Lu, H.; Fu, Z.F. Enhancement of Blood-Brain Barrier Permeability and Reduction of Tight Junction Protein Expression Are Modulated by Chemokines/Cytokines Induced by Rabies Virus Infection. J. Virol. 2014, 88, 4698-4710. [CrossRef]

45. Jung, H.K.; Ryu, H.J.; Kim, M.-J.; Kim, W.I.; Choi, H.K.; Choi, H.-C.; Song, H.-K.; Jo, S.-M.; Kang, T.-C. Interleukin-18 attenuates disruption of brain-blood barrier induced by status epilepticus within the rat piriform cortex in interferon-gamma independent pathway. Brain Res. 2012, 1447, 126-134. [CrossRef]

46. Fu, A.K.Y.; Hung, K.-W.; Yuen, M.Y.F.; Zhou, X.; Mak, D.S.Y.; Chan, I.C.W.; Cheung, T.H.; Zhang, B.; Fu, W.-Y.; Liew, F.Y.; et al. IL-33 ameliorates Alzheimer's disease-like pathology and cognitive decline. Proc. Natl. Acad. Sci. USA 2016, 113, E2705-E2713. [CrossRef] 
47. Reverchon, F.; Mortaud, S.; Sivoyon, M.; Maillet, I.; Laugeray, A.; Palomo, J.; Montécot, C.; Herzine, A.; Meme, S.; Meme, W.; et al. IL-33 receptor ST2 regulates the cognitive impairments associated with experimental cerebral malaria. PLoS Pathog. 2017, 13, e1006322. [CrossRef]

48. Lotfi, N.; Thome, R.; Rezaei, N.; Zhang, G.X.; Rostami, A.; Esmaeil, N. Roles of GM-CSF in the pathogenesis of autoimmune diseases: An update. Eur. J. Immunol. 2019, 49, 938-939. [CrossRef] [PubMed]

49. Goebel, K.; Asaridou, C.-M.; Merker, M.; Eichler, S.; Herrmann, A.M.; Geuss, E.; Ruck, T.; Schuengel, L.; Groeneweg, L.; Narayanan, V.; et al. Plasma kallikrein modulates immune cell trafficking during neuroinflammation via PAR2 and bradykinin release. Proc. Natl. Acad. Sci. USA 2019, 116, 271-276. [CrossRef]

50. Tian, Y.; Gawlak, G.; Shah, A.S.; Higginbotham, K.; Tian, X.; Kawasaki, Y.; Akiyama, T.; Sacks, D.B.; Birukova, A.A. Hepatocyte Growth Factor-induced Asef-IQGAP1 Complex Controls Cytoskeletal Remodeling and Endothelial Barrier. J. Biol. Chem. 2015, 290, 4097-4109. [CrossRef]

51. Sweeney, M.; Foldes, G. Takes Two: Endothelial-Perivascular Cell Cross-Talk in Vascular Development and Disease. Front. Cardiovasc. Med. 2018, 5. [CrossRef] [PubMed]

52. Yang, L.; Zhang, Y.; Ma, Y.; Du, J.; Gu, L.; Zheng, L.; Zhang, X. Effect of melatonin on EGF- and VEGF-induced monolayer permeability of HUVECs. Am. J. Physiol. Circ. Physiol. 2019, 316, H1178-H1191. [CrossRef] [PubMed]

53. Shibuya, M. Vascular Endothelial Growth Factor (VEGF) and Its Receptor (VEGFR) Signaling in Angiogenesis: A Crucial Target for Anti- and Pro-Angiogenic Therapies. Genes Cancer 2011, 2, 1097-1105. [CrossRef]

54. Rahimi, N. Defenders and Challengers of Endothelial Barrier Function. Front. Immunol. 2017, 8. [CrossRef]

55. Argaw, A.; Asp, L.; Zhang, J.; Navrazhina, K.; Pham, T.; Mariani, J.; Mahase, S.; Dutta, D.; Seto, J.; Kramer, E.; et al. Astrocytederived VEGF-A drives blood-brain barrier disruption in CNS inflammatory disease. Mult. Scler. J. 2013, 19, 134. [CrossRef]

56. Greenberg, J.I.; Shields, D.J.; Barillas, S.G.; Acevedo, L.M.; Murphy, E.; Huang, J.; Scheppke, L.; Stockmann, C.; Johnson, R.S.; Angle, N.; et al. A role for VEGF as a negative regulator of pericyte function and vessel maturation. Nature 2008, 456, 806-813. [CrossRef]

57. Lin, C.-I.; Chen, C.-N.; Huang, M.-T.; Lee, S.-J.; Lin, C.-H.; Chang, C.-C.; Lee, H. Lysophosphatidic acid upregulates vascular endothelial growth factor-C and tube formation in human endothelial cells through LPA(1/3), COX-2, and NF-kappa B activationand EGFR transactivation-dependent mechanisms. Cell. Signal. 2008, 20, 1804-1814. [CrossRef]

58. Simmons, S.; Erfinanda, L.; Bartz, C.; Kuebler, W.M. Novel mechanisms regulating endothelial barrier function in the pulmonary microcirculation. J. Physiol. 2019, 597, 997-1021. [CrossRef]

59. Scheppke, L.; Murphy, E.A.; Zarpellon, A.; Hofmann, J.J.; Merkulova, A.; Shields, D.J.; Weis, S.M.; Byzova, T.V.; Ruggeri, Z.M.; Iruela-Arispe, M.L.; et al. Notch promotes vascular maturation by inducing integrin-mediated smooth muscle cell adhesion to the endothelial basement membrane. Blood 2012, 119, 2149-2158. [CrossRef]

60. Hartmann, C.; Zozulya, A.; Wegener, J.; Galla, H.-J. The impact of glia-derived extracellular matrices on the barrier function of cerebral endothelial cells: An in vitro study. Exp. Cell Res. 2007, 313, 1318-1325. [CrossRef]

61. Winkler, E.A.; Bell, R.D.; Zlokovic, B.V. Central nervous system pericytes in health and disease. Nat. Neurosci. 2011, 14, 1398-1405. [CrossRef]

62. Perrot, C.Y.; Herrera, J.L.; Fournier-Goss, A.E.; Komatsu, M. Prostaglandin E2 breaks down pericyte-endothelial cell interaction via EP1 and EP4-dependent downregulation of pericyte N-cadherin, connexin-43, and R-Ras. Sci. Rep. 2020, 10. [CrossRef]

63. Li, M.W.M.; Mruk, D.D.; Lee, W.M.; Cheng, C.Y. Connexin 43 is critical to maintain the homeostasis of the blood-testis barrier via its effects on tight junction reassembly. Proc. Natl. Acad. Sci. USA 2010, 107, 17998-18003. [CrossRef] [PubMed]

64. Nagasawa, K.; Chiba, H.; Fujita, H.; Kojima, T.; Saito, T.; Endo, T.; Sawada, N. Possible involvement of gap junctions in the barrier function of tight junctions of brain and lung endothelial cells. J. Cell. Physiol. 2006, 208, 123-132. [CrossRef]

65. Weiss, A.; Attisano, L. The TGFbeta Superfamily Signaling Pathway. Wiley Interdiscip. Rev. Dev. Boil. 2013, 2, 47-63. [CrossRef] [PubMed]

66. Horiguchi, M.; Ota, M.; Rifkin, D.B. Matrix control of transforming growth factor-beta function. J. Biochem. 2012, 152, 321-329. [CrossRef] [PubMed]

67. Nitta, T.; Hata, M.; Gotoh, S.; Seo, Y.; Sasaki, H.; Hashimoto, N.; Furuse, M.; Tsukita, S. Size-selective loosening of the blood-brain barrier in claudin-5-deficient mice. J. Cell Biol. 2003, 161, 653-660. [CrossRef]

68. Engelhardt, S.; Al-Ahmad, A.J.; Gassmann, M.; Ogunshola, O.O. Hypoxia Selectively Disrupts Brain Microvascular Endothelial Tight Junction Complexes through a Hypoxia-Inducible Factor-1 (HIF-1) Dependent Mechanism. J. Cell. Physiol. 2014, 229, 1096-1105. [CrossRef]

69. Liu, J.; Jin, X.; Liu, K.J.; Liu, W. Matrix Metalloproteinase-2-Mediated Occludin Degradation and Caveolin-1-Mediated Claudin-5 Redistribution Contribute to Blood-Brain Barrier Damage in Early Ischemic Stroke Stage. J. Neurosci. 2012, 32, $3044-3057$. [CrossRef]

70. Sladojevic, N.; Stamatovic, S.M.; Johnson, A.M.; Choi, J.; Hu, A.; Dithmer, S.; Blasig, I.E.; Keep, R.F.; Andjelkovic, A.V. Claudin-1Dependent Destabilization of the Blood-Brain Barrier in Chronic Stroke. J. Neurosci. 2019, 39, 743-757. [CrossRef]

71. Kale, G.; Naren, A.P.; Sheth, P.; Rao, R.K. Tyrosine phosphorylation of occludin attenuates its interactions with ZO-1, ZO-2, ZO-3. Biochem. Biophys. Res. Commun. 2003, 302, 324-329. [CrossRef]

72. Wang, Y.L.; Hui, Y.N.; Guo, B.; Ma, J.X. Strengthening tight junctions of retinal microvascular endothelial cells by pericytes under normoxia and hypoxia involving angiopoietin-1 signal way. Eye 2007, 21, 1501-1510. [CrossRef] [PubMed] 
73. Worzfeld, T.; Schwaninger, M. Apicobasal polarity of brain endothelial cells. J. Cereb. Blood Flow Metab. 2016, 36, 340-362. [CrossRef] [PubMed]

74. Dragoni, S.; Turowski, P. Polarised VEGFA Signalling at Vascular Blood-Neural Barriers. Int. J. Mol. Sci. 2018, 19. [CrossRef]

75. Thomsen, L.B.; Burkhart, A.; Moos, T. A Triple Culture Model of the Blood-Brain Barrier Using Porcine Brain Endothelial cells, Astrocytes and Pericytes. PLoS ONE 2015, 10. [CrossRef]

76. Bryan, B.A.; D'Arnore, P.A. Pericyte isolation and use in endothelial/pericyte coculture models. Mehods Enzym. 2008, 443, 315-331. [CrossRef]

77. Kulczar, C.; Lubin, K.E.; Lefebvre, S.; Miller, D.W.; Knipp, G.T. Development of a direct contact astrocyte-human cerebral microvessel endothelial cells blood-brain barrier coculture model. J. Pharm. Pharmacol. 2017, 69, 1684-1696. [CrossRef] [PubMed]

78. Brandt, M.M.; van Dijk, C.G.M.; Maringanti, R.; Chrifi, I.; Kramann, R.; Verhaar, M.C.; Duncker, D.J.; Mokry, M.; Cheng, C. Transcriptome analysis reveals microvascular endothelial cell-dependent pericyte differentiation. Sci. Rep. 2019, 9. [CrossRef] 